\title{
Length and Dimensional Measurements at NIST
}

\section{Dennis A. Swyt}

National Institute of Standards and Technology, Gaithersburg, MD 20899-8201

dennis.swyt@nist.gov
This paper discusses the past, present, and future of length and dimensional measurements at NIST. It covers the evolution of the SI unit of length through its three definitions and the evolution of NBS-NIST dimensional measurement from early linescales and gage blocks to a future of atom-based dimensional standards. Current capabilities include dimensional measurements over a range of fourteen orders of magnitude. Uncertainties of measurements on different types of material artifacts range down to $7 \times 10^{-8} \mathrm{~m}$ at $1 \mathrm{~m}$ and 8 picometers (pm) at $300 \mathrm{pm}$. Current work deals with a broad range of areas of dimensional metrology. These include: large-scale coordinate systems; complex form; microform; surface finish; two-dimensional grids; optical, scanning-electron, atomic-force, and scanning-tunneling microscopies; atomic-scale displacement; and atombased artifacts.

Key words: atomic-force; dimensional; interferometry; length; measurements; microscopes; optical; scanning-electron; scanning-tunneling; traceability.

Available online: http://www.nist.gov/jres

\section{Contents}

1. Introduction........................... 2

1.1 The Evolution of the Meter Since 1901.......... 2

1.1.1 The Re-Definitions of the Meter......... 2

1.1.2 NIST Contributions to the Re-definitions of the Unit of Length ............. 3

1.2 The Evolution of Dimensional Metrology Since 1901. 3

1.2.1 Two Historical Dimensional Measurements ... 3

1.2.1.1 Measurement of Linescales Since $1901 \ldots \ldots \ldots \ldots \ldots \ldots \ldots . . \ldots$

1.2.1.2 Measurement of Precision Gage Blocks Since 1901 ...............

1.2.2 Some NIST Contributions to the Dimensional Metrology Since $1901 \ldots \ldots \ldots \ldots \ldots \ldots$. . . . 4

1.3 Industrial Driver for Lower Uncertainties in Standards: Tightening Tolerances.................. 5

1.3.1 NIST Uncertainty Relative to Industry Tolerances..................... 5

1.3.2 The Trend of Tightening Tolerances ........ 5

2. Dimensional Metrology at NIST Today ........... 5

2.1 The State of NIST Dimensional Measurement

Services Provided.
2.2 Research and Development in Dimensional Metrology at NIST Today............... 7 2.2.1 The First-Principles Method of NIST Dimensional Measurements.............. 7 2.2.1.1 The Artifact ............... 8 2.2.1.2 The Measuring Machine......... 8

2.2.1.3 The Theoretical Model........... 10

2.2.1.4 The Measurement Algorithm....... 11

2.2.2 Needs of Some Key Industries in Dimensional Metrology.................... 11

2.2.2.1 Aircraft Industry .............. 11

2.2.2.2 Automotive Industry........... 12

2.2.2.3 Computer Industry . . . . . . . . . . 12

2.2.2.4 Microelectronics Industry. . . . . . . 12

2.3 Current Work ...................... 12

2.3.1 Large-Scale Coordinate Metrology ......... 12

2.3.2 Dilatometry ..................... 13

2.3.3 Complex Form Metrology . . . . . . . . . . . 13

2.3.4 Microform Metrology ............. 13

2.3.5 Surface Finish Metrology ............. 13 
2.3.6 Two-Dimensional Metrology............ 14

2.3.7 Optical Metrology .................. 14

2.3.8 SEM Metrology .................. 14

2.3.9 Scanned-Probe-Microscope Metrology . . . . . . 14

2.3.10 Atom-Based Artifact Standards . . . . . . . . 14

2.3.11 Atomic-Scale Displacement Metrology...... 15

3. The Future ........................ 15

3.1 Limits: Ultimate, Standards-Based, and Practical .... 15

3.1.1 Ultimate Theoretical Limits ............. 15

3.1.1.1 Quantization of Space........... 15

3.1.1.2 Heisenberg Uncertainty Principle ... 16

3.1.1.3 Johnson kT Noise ............. 16

3.1.2 Limits from Primary Reference Standards .... 16

3.1.2.1 Primary Reference Standards for the

Second and the Meter.......... 16

3.1.2.2 Temperature Standard and Length of

Material Objects............... 16

3.1.3 Practical Limits .................. 16

3.1.3.1 Displacement Interferometry ...... 17

3.1.3.2 Probe Limitations ............. 17

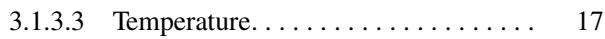

3.2 Industry Trends...................... 18

3.2.1 Emergence of the New Traceability ........ 19

3.2.2 Increasing Demand for Calibrated Artifacts... 19

3.2.3 Development of GPS Chain of Standards.... 19

3.3 The Evolving NIST Response .............. 19

3.3.1 Atom-Based Artifacts Standards ......... 19

3.3.2 Use of Other Government Capabilities ..... 19

3.3.3 Use of Industry Capabilities ............ 20

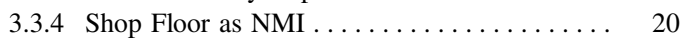

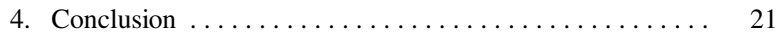

5. References.......................... 21

\section{Introduction}

One of the most venerable, commonly encountered, scientifically fundamental, and economically important units of measure is length. It is one of the fundamental measurement quantities in physics, commerce, and everyday life. The international standard of length is the meter, one of the seven base units of the modern International System of Units (SI) and one of the two original units of the international system of standards upon which the SI is based. Both the meter as the unit of length and dimensional measurements based on the meter have undergone substantial changes over the lifetime of the National Bureau of Standards and its successor, the National Institute of Standards and Technology.

\subsection{The Evolution of the Meter Since 1901}

Three different definitions of the international standard of length have been in effect during the lifetime of NBS-NIST. At the time of the founding of the National Bureau of Standards in 1901, the international standard of length was the International Prototype Meter. The meter was defined at that time as the distance between two lines ruled on a platinum-iridium bar carefully preserved in a special vault at the International Bureau of Weights and Measures (BIPM) near Paris [1]. With its founding, NBS became the keeper of a duplicate of this bar, Meter No. 27, which then served as the U.S. national standard of length for 60 years. At the end of that period, the meter as the international standard of length underwent the first of two fundamental re-definitions.

\subsubsection{The Re-Definitions of the Meter}

In 1960, the meter was re-defined by the General Conference on Weights and Measures (CGPM) to be 1659763.73 vacuum wavelengths of light resulting from the unperturbed atomic energy level transition $2 p_{10}-5 d_{5}$ of the krypton isotope having a relative atomic mass of 86 [2].

In 1983, the meter was re-defined again to the one in effect today, namely: "The meter is the length of path traveled by light in vacuum during the interval of 1/299 792.458 of a second" [3]. (Among the effects of the definition is that it fixes the speed of light in vacuum to be exactly 299792.458 meters per second). At that time, the International Committee on Weights and Measures (CIPM) gave three basic methods for the practical realization of the meter: time-of-flight, using time intervals, and interferometry, using wavelengths or frequencies. CIPM gave five recommended radiations with assigned frequencies, wavelengths, and uncertainties. Of the recommended radiations, that of the iodinestabilized helium-neon laser is the most widely used for practical realization of the meter. It has a wavelength of $\lambda_{\mathrm{HeNe}}=632.99139822 \mathrm{~nm}$, with a relative standard uncertainty $u_{\mathrm{r}}$ of $2.5 \times 10^{-11}$ [4].

The effect of the re-definitions and advances in measurement of the frequencies of recommended radiations was to decrease the relative uncertainty attainable in realization of the meter by five orders of magnitude

- from an estimated $2 \times 10^{-6}$ (this paper's estimate of the reproducibility with which the first transfer could be made from the prototype meter bar) [5],

- through $7 \times 10^{-8}$ (the relative uncertainty for the wavelength emitted by cadmium discharge lamps, a secondary standard of length),

- through $4 \times 10^{-9}$ (the relative uncertainty for the wavelength emitted by krypton-86 discharge lamps),

- to $2.5 \times 10^{-11}$ (the CIPM specified uncertainty for the visible wavelength of the iodine-stabilized helium-neon laser today) [4]. 


\subsubsection{NIST Contributions to the Re-definitions of the Unit of Length}

The unit of length has evolved from a definition based on a physical prototype through one based on a specific wavelength of light to one based on an electromagnetic wave propagating in free space. NIST has made substantial contributions to this evolution. These contributions include:

- Production in 1947 of isotopically pure mercury198, measurement of its spectral linewidth and proposal of its wavelength for adoption as the international standard of length [6];

- Measurement in 1971 of the spectral linewidth and frequency of an emission line of a helium-neon laser corresponding closely to an absorption line of iodine, then a candidate for a recommended radiation for the re-definition of the meter to replace that of krypton-86, the standard for definition of the meter at the time [7];

- Measurement in 1976 of the ratio of the wavelength of an iodine-stabilized $\mathrm{HeNe}$ laser to that of a methane-stabilized He-Ne laser, providing a provisional extension of the frequency scale based on the cesium oscillator into the visible spectrum [8];

- Development in 1980 of a portable iodine-absorption-stabilized helium-neon laser for use in international metrology [9];

- Measurement in 1983 of the frequencies of visiblelight lasers, including that of the iodine-stabilized laser, directly against that of the cesium-beam atomic clock, the primary standard of time [10].

\subsection{The Evolution of Dimensional Metrology Since 1901}

The definition of the meter-whether in terms of a prototype meter bar, a wavelength of light, or the propagation of an electromagnetic wave in an interval of time-has provided the basis for the lowest-uncertainty realization of the unit. A primary economic driver for reduced uncertainty with which the meter could be realized has been demands for reduced uncertainty in measurements made in commerce, especially by manufacturers using leading-edge technology in the production of goods. These measurements are not of the "Platonic length" of wavelengths of light propagating in free space but of the physical lengths of material objects, from aircraft wings and automobile engine parts to microelectronic devices. Measurements of dimensions of material goods are most often referenced to the SI unit of length through material artifacts calibrated as dimensional standards. NIST has played a key role for the United States as provider of the link between the Platonic length of the laboratory and the physical length of material objects through its practice of dimensional metrology.

\subsubsection{Two Historical Dimensional Measurements}

Two mainstays of NIST dimensional metrology over the lifetime of NBS-NIST have been measurements of linescales and gage blocks.

\subsubsection{Measurement of Linescales Since 1901}

The lowest uncertainty attained in dimensional measurement of a material object occurs in the calibration of linescales. The dimensional feature of interest in a linescale is the distance between parallel lines inscribed on a substrate.

By 1904, NBS was providing calibrations of linescales relative to the U.S. prototype meter bar for scales from $100 \mathrm{~mm}$ to $50 \mathrm{~m}$ in length with subdivisions down to $0.1 \mathrm{~mm}$ [6]. Today, NIST provides calibrations of linescales relative to first-principles realizations of the meter using displacement interferometry. These calibrations range from scales as small as $10 \mu \mathrm{m}$ in length (with subdivisions down to $1 \mu \mathrm{m}$ ) to as long as $50 \mathrm{~m}$ (with subdivisions down to $0.1 \mathrm{~mm}$ ) [11].

Changes have occurred over the century in how NBS-NIST has stated its estimate of the closeness of the value of the quantity being measured to the result of a measurement-from no statement, to that of maximum likely error, to accuracy, and now to uncertainty. As a result, it is not possible to estimate the standard uncertainty of measurement results for those reported over the period. However, a reasonable characterization is that:

- For the period from 1904-1960, the reproducibility of measurements against the U.S. prototype meter bar is estimated to be of the order of $0.25 \mu \mathrm{m}$, in relative terms, $2.5 \times 10^{-7}$ at $1 \mathrm{~m}$, with the legibility of the lines on the bar the major limitation [5].

- For the period from 1960-2000, the expanded uncertainty $U$ (coverage factor $k=2$ ) for measurements of one-meter linescales by interferometry against a wavelength of light decreased progressively from $0.25 \mu \mathrm{m}$ in 1960 to $0.08 \mu \mathrm{m}\left(8 \times 10^{-8}\right.$ at $\left.1 \mathrm{~m}\right)$ today, due to improvements in measuring machine geometry, light sources, and temperature measurement and control [11].

Figure 1 shows the NIST Line Scale Interferometer System, first introduced in 1965, as it appeared in 1971. 


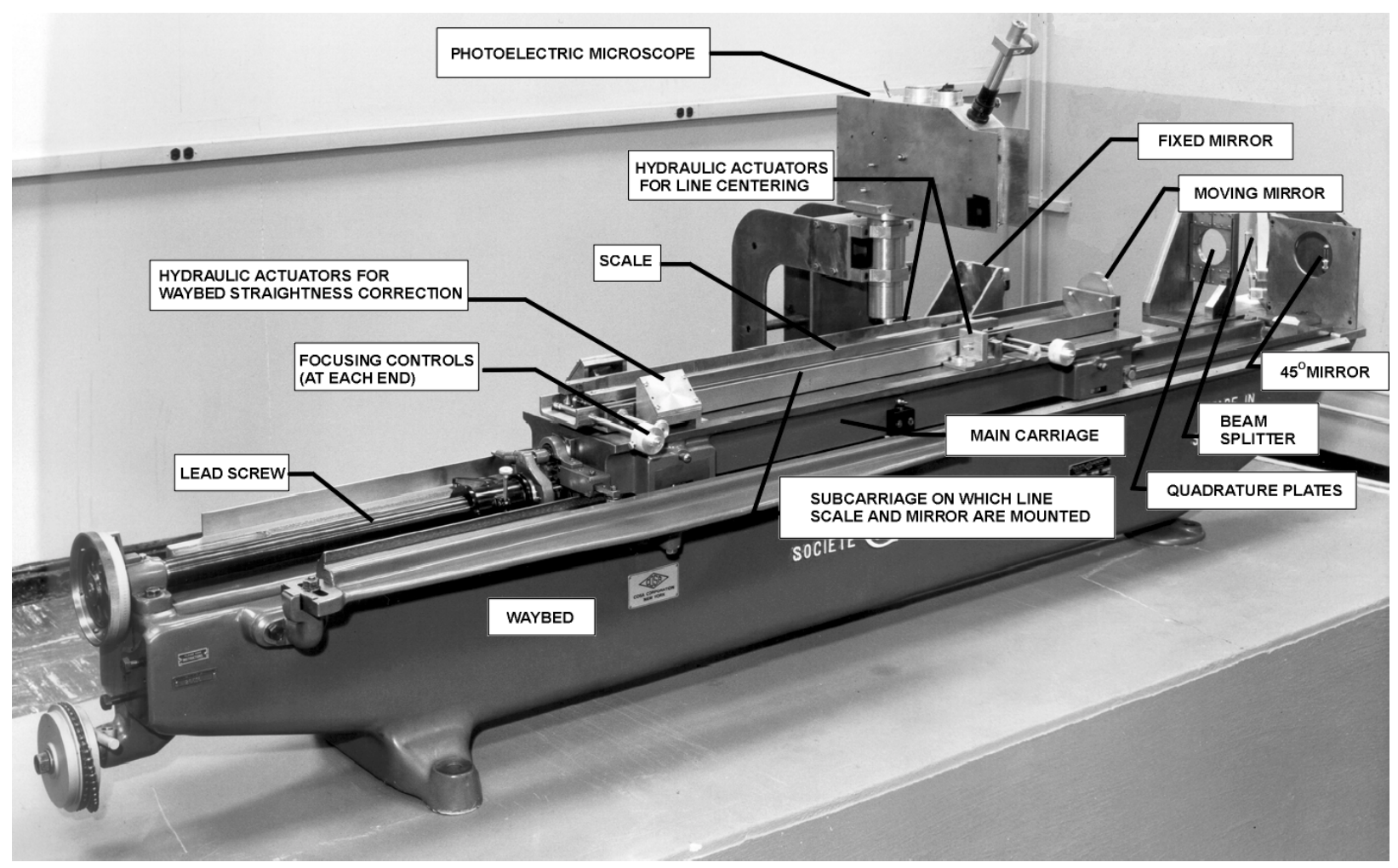

Fig. 1. The NIST line scale interferometer system as it appeared starting in 1971 [11]. It was first introduced into service in 1965.

\subsubsection{Measurement of Precision Gage Blocks Since 1901}

One of the most industrially important lengthmeasurement standards, particularly for machine-toolbased manufacturing, is precision gage blocks. Consisting of blocks of metal, usually steel, having two opposite faces that are plane, parallel, and a specified distance apart, they are used in manufacturing as size blocks for precise mechanical work and for checking precise mechanical work.

Prior to 1917 , NBS is reported to have been calibrating precision gage blocks with mechanical-contact comparators against end standards calibrated by visualmicroscope comparison to linescales calibrated by visual-microscope comparison to the U.S. prototype meter bar. Based on the "error" in the process then reported, today's estimate of the uncertainty of those earliest NBS calibrations of precision gage blocks is $0.75 \mu \mathrm{m}\left(7.5 \times 10^{-4}\right.$ at $\left.1 \mathrm{~mm}\right)$.

In 1922, NBS introduced its first interferometric measurements of gage blocks, reducing the estimated uncertainty by an order of magnitude to $0.075 \mu \mathrm{m}$ $\left(7.5 \times 10^{-5}\right.$ at $\left.1 \mathrm{~mm}\right)$. In 1935 , NBS reportedly gained another factor of three improvement to an estimated uncertainty of $0.025 \mu \mathrm{m}\left(2.5 \times 10^{-5}\right.$ at $\left.1 \mathrm{~mm}\right)$. With other improvements, especially improvement of the geometry and material-stability of the blocks in 1960 [6], the limiting expanded uncertainty (coverage factor $k=2)$ for short blocks today is $0.008 \mu \mathrm{m}\left(8 \times 10^{-6}\right.$ at $1 \mathrm{~mm})$ [12], an improvement of two orders of magnitude over the lifetime of NBS-NIST.

\subsubsection{Some NIST Contributions to Dimensional Metrology Since 1901}

NBS has made fundamental contributions to the evolution of dimensional measurements over the period since the founding of NBS to the era of current work, which reaches back to the beginning of the last decade of the twentieth century. These fundamental contributions include:

- Introduction in 1922 of interferometric measurements of precision gage blocks [13]

- Development in 1961 of high-stability precision gage blocks [6]

- Creation in 1968 of the first scanned probe topography measuring instrument, a field-emission device that was the precursor of the scanning tunneling microscope and that was cited in the Nobel Prize award for that device [14] 
- Development in 1976 of the technique for the lowuncertainty optical-microscope measurement of microelectronic photomask linewidths [15]

- Development in 1977 of the technique of computerbased real-time correction of systematic errors in positioning of coordinate measuring machines [16]

- Development in 1981 of the technique for laserinterferometer-based scanning-electron-microscope measurement of microelectronic photomask linewidths [17]

\subsection{The Industrial Driver for Lower Uncertainties in Standards: Tightening Tolerances}

The need for reduced uncertainty in the "primary standard" aspect of length, that is, in its definition and realization, and in the "secondary standard" aspect, that is, in its transfer and dissemination through dimensional metrology, is linked strongly to tightening tolerances in industrial manufacturing.

\subsubsection{NIST Uncertainty Relative to Industry Tolerances}

The basic logic is that measurements made by NBSNIST as the national metrology institute responsible for realization and dissemination of the SI unit of length need to be at levels of uncertainty that are small fractions of the tightest tolerances achieved in manufacturer's use of leading-edge technology. NBS length metrologists' explicitly used this line of reasoning within two decades of NBS' founding [13]. It is still valid today.

In order to assess with confidence the conformance of parts to tolerances, the uncertainty associated with the gages employed was required to be some fraction of the tolerance on the dimensions of the part being measured. In other words, the uncertainty associated with measurements made with the gage was required to be equal to the value of the tolerance divided by some factor. In a 1918 treatise on industrial measurement and inspection, the gage uncertainty was required to be less than the part tolerance by a factor of four (or five, depending upon round-off to the nearest half-digit) [18]. By the same reasoning, the uncertainty of the process of calibration of the gage was required to be a second factor of four smaller than the desired gage uncertainty.

According to a 1922 NBS paper on interferometric measurement of gage blocks [13], NBS' calibration of the testing laboratory's standards was, in turn, required to be a third factor smaller than that of the gage uncertainty. As a result of these three successive reductions by factors of four or five (less round-off at various levels), the uncertainty required of NBS calibrations at that time was deemed to be of the order of $1 / 100$ of the more demanding part tolerances of the day.

Now a common machining tolerance of the time was reportedly $\pm 50 \mu \mathrm{m}$ [18] and the uncertainty of NBS calibrations of gage blocks prior to 1917 was $0.5 \mu \mathrm{m}$ to $1.0 \mu \mathrm{m}$ [13]. Thus the lower end of the NBS uncertainty was smaller by the requisite factor of 100 than the commonly called-for tolerance (presumably a highaccuracy tolerance for an earlier decade). By 1917, however, the tolerance of a high-accuracy part was $\pm 6.25 \mu \mathrm{m}$ [18], and, tolerances of $\pm 2.5 \mu \mathrm{m}$ were being sought [13]. In order to provide calibrations a factor of 100 better than that latter tolerance, NBS advanced its measurement capabilities to provide calibrations of gage blocks with an uncertainty of the required $\pm 0.025 \mu \mathrm{m}$ [13].

\subsubsection{The Trend of Tightening Tolerances}

The trend of tightening tolerances and the consequent need for lower uncertainties at NBS-NIST as first suggested in 1922 [13] have continued unabated throughout the lifetime of NBS-NIST. According to an 1980 academic analysis of industrial trends in ultraprecision machining over the central decades of the twentieth century, achievable machining tolerances for particular classes of processes has decreased at a rate of approximately an order of magnitude every twenty years [19]. By this account, the tolerances achievable by what is described as normal precision machining have decreased from the order of $10 \mu \mathrm{m}$ in the period 1920 to 1940 to less than $1 \mu \mathrm{m}$ in the period 1980 to today. The analysis also indicated an evolution of a parallel, ultra-precision machining regime-which includes atomic-, molecular-, and ion-beam milling and semiconductor-lithography processes-that has tolerances an order of magnitude smaller than those of the normal precision regime. In this ultra-precision regime, attainable tolerances have decreased from the order of $1 \mu \mathrm{m}$ in the period 1920 to 1940 to the order of $1 \mathrm{~nm}$ to $10 \mathrm{~nm}$ today.

\section{Dimensional Metrology at NIST Today}

Today, the NIST division responsible for the realization and dissemination of the SI unit of length serves a range of industries, from aircraft and automotive to computers and microelectronics. It provides fourteen major types of length measurement services to approximately 120 different fee-paying institutional customers per year. Each measurement service begins with a first-principles realization of the SI unit of length via frequency-stabilized lasers and displacement interferometry. The measurement technologies employed 
include laser-ranging devices, theodolites, large-scale coordinate measuring machines (CMMs), optical- and ultraviolet-light microscopes, scanning electron microscopes (SEMs), atomic force microscopes (AFMs), and scanning tunneling microscopes (STMs).

\subsection{The State of NIST Dimensional Measurement Services}

Table 1 describes a number of the types of length measurements provided by NIST today. Shown in the table for each type are: range; expanded uncertainty; relative expanded uncertainties at respective ends of the range; and an assessment of where the uncertainty stands relative to the best provided by other national metrology institutes (NMIs).

Representing the largest dimensions that NIST calibrates are surveyor's measuring tapes, one type of linescale. The $50 \mathrm{~m}$ length of such measuring tapes can be calibrated to an expanded uncertainty (coverage factor $k=2$ ) of $500 \mu \mathrm{m}$ or, fractionally, $1 \times 10^{-5}$ at $50 \mathrm{~m}$. According to a benchmarking of NIST measurement services against those of eleven other NMIs, including all of the major industrialized countries, these uncertainties tie NIST with one other NMI for providing the lowest uncertainty [20].

Representing the lowest relative uncertainty $(U / L)$ of dimensional measurements provided in a NIST calibration is that of the length of a $1 \mathrm{~m}$ linescale. In this case, the relative expanded uncertainty (coverage factor $k=2)$ is $7 \times 10^{-8}$ at $1 \mathrm{~m}$ [11]. According to the NIST benchmarking study cited, this is also the lowest uncertainty of a dimensional measurement of a material artifact provided by any of the world's NMIs [20].
Representing the lowest uncertainty of linescale measurements is that on the $1 \mu \mathrm{m}$ subdivision of a scale of $10 \mu \mathrm{m}$ in overall length. The attainable expanded uncertainty (coverage factor $k=2$ ) for these short linescales is $1 \mathrm{~nm}$ [11]. According to the NIST benchmarking study, this is also the lowest absolute uncertainty of a linescale measurement provided by any of the world's NMIs [20].

Representing the lowest relative uncertainty of an end standard is that of the $1 \mathrm{~m}$ step on a CMM step gage [12]. According to the NIST benchmarking study, with its relative expanded uncertainty (coverage factor $k=2$ ) of $7 \times 10^{-7}$, NIST is tied with one other NMI in providing this level of uncertainty [20].

Representing the state-of-the-art of precision gage block calibration is the expanded uncertainty of $10 \mathrm{~nm}$ to $30 \mathrm{~nm}$ on gage blocks of $10 \mathrm{~mm}$ to $1000 \mathrm{~mm}$ in length [12]. According to the NIST benchmarking study, the NIST uncertainty is that attained by the group of the leading NMIs of the world [20].

Representing the lowest uncertainty of end-standardtype measurements in the microscopic regime is that of sub-micrometer and micrometer linewidths of the NIST photomask linewidth standards, with an expanded uncertainty of $36 \mathrm{~nm}$ over the range of lines from $0.5 \mu \mathrm{m}$ to $30 \mu \mathrm{m}$ width [23]. According to the NIST benchmarking study, NIST is the first provider of such standards and provides the lowest uncertainty [20].

Finally, representing the lowest reported uncertainty ever attained in an SI-traceable dimensional measurement of an individual material feature is that of the step height of fabricated single-atom steps of silicon (111). The expanded uncertainty (coverage factor $k=2$ ) of measurement of the 304 picometer (pm) step height is $8 \mathrm{pm}[24,25]$.

Table 1. Ranges and uncertainties of selected NIST dimensional measurement capabilities

\begin{tabular}{|c|c|c|c|c|c|}
\hline $\begin{array}{l}\text { Measurement } \\
\text { types }\end{array}$ & $\begin{array}{c}\text { Range } \\
\left(L_{\min } \text { to } L_{\max }\right)\end{array}$ & $\begin{array}{l}\text { Uncertainty } U \\
\quad(k=2)\end{array}$ & $U / L_{\min }$ & $U / L_{\max }$ & $\begin{array}{c}\text { Relative to leading } \\
\text { NMI }\end{array}$ \\
\hline \multicolumn{6}{|c|}{ Linescales } \\
\hline Measuring tapes [20] & $1 \mathrm{~m}$ to $50 \mathrm{~m}$ & $60 \mu \mathrm{m}$ to $500 \mu \mathrm{m}$ & $6 \times 10^{-5}$ & $1 \times 10^{-5}$ & Tied with leader \\
\hline Linescales ("long") [11] & $10 \mu \mathrm{m}$ to $1 \mathrm{~m}$ & $1 \mathrm{~nm}$ to $70 \mathrm{~nm}$ & $1 \times 10^{-3}$ & $7 \times 10^{-8}$ & Leader \\
\hline Linescales ("short") [11] & $1 \mu \mathrm{m}$ to $10 \mu \mathrm{m}$ & $1 \mathrm{~nm}$ & $1 \times 10^{-3}$ & $1 \times 10^{-4}$ & Leader \\
\hline \multicolumn{6}{|c|}{ End standards } \\
\hline CMM step gages [21] & $100 \mathrm{~mm}$ to $1 \mathrm{~m}$ & $0.4 \mu \mathrm{m}$ to $0.7 \mu \mathrm{m}$ & $4 \times 10^{-6}$ & $7 \times 10^{-7}$ & Tied with leader \\
\hline Gage blocks [22] & $1 \mathrm{~mm}$ to $100 \mathrm{~mm}$ & $10 \mathrm{~nm}$ to $30 \mathrm{~nm}$ & $1 \times 10^{-5}$ & $3 \times 10^{-7}$ & Same as leading NMIs \\
\hline IC photomask linewidth [23] & $0.5 \mu \mathrm{m}$ to $30 \mu \mathrm{m}$ & $36 \mathrm{~nm}$ & $7 \times 10^{-2}$ & $1.2 \times 10^{-3}$ & Leader \\
\hline Step height $[24,25]$ & $300 \mathrm{pm}$ to $75 \mu \mathrm{m}$ & $8 \mathrm{pm}$ to $0.4 \mu \mathrm{m}$ & $2.5 \times 10^{-2}$ & $5 \times 10^{-3}$ & Leader \\
\hline
\end{tabular}




\subsection{Research and Development in Dimensional Metrology at NIST Today}

Given the trend to tightening tolerances in precision machining and the goal of a factor of 100 for NIST to surpass the tightest tolerances in the manufacturing it supports, NIST would be expected to provide measurements with uncertainties of the order of tens of nanometers to support what has been called the "normal precision machining" regime and of the order of tens of picometers to support the "ultra-precision" regime. For one particular standard for each regime, NIST can be viewed as meeting those projections. For the normal machining regime, NIST provides calibrations of precision gage blocks with a state-of-the-art expanded uncertainty (coverage factor $k=2$ ) of $10 \mathrm{~nm}$. In the "ultra-precision machining" regime, NIST can perform measurements of single-atom steps in silicon with an expanded uncertainty of $8 \mathrm{pm}$. At the same time, NIST is carrying out extensive research and development to address anticipated U.S. industry needs for new types of dimensional measurements and reduced uncertainties.

\subsubsection{The First-Principles Method of NIST Dimensional Measurements}

Today, possibly more so than at any time in its history, NIST is called upon to meet extraordinary demands of U.S. manufacturing industries in their use of leadingedge technologies with state-of-the-art dimensional tolerances. These extraordinary demands include:

(1) uncertainties for dimensional measurements on production devices that are beyond the world stateof-the-art in measurement capability [26]; and

(2) traceability to a measurement by an NMI of a "primary standard" of the particular dimensional feature of their discrete-part product, that is, what is now being called measurement-task-specific traceability [27]; and, in some cases.

(3) both state-of-the-art uncertainty and NMI traceability in the same measurement.

Demands from industry for NIST to develop lowuncertainty, task-specific, "primary-standard" measurements often arise when there is an unresolved discrepancy between different, highly reproducible results of measurements made respectively by producers of and customers for economically important products with state-of-the-art dimensional tolerances. The circumstances of such an unresolved discrepancy in measurement results are frequently as follows:
- In order to achieve a critical function of a businesscritical product, a company (in this scenario, one in an economically important industry) designs a part to a tight dimensional tolerance.

- A manufacturer produces the critically dimensioned part.

- In order to achieve the tight tolerance, the manufacturer uses a manufacturing process that produces parts to high precision with high reproducibility.

- To assure conformity of the part to the customerspecified tolerance, the manufacturer makes measurements of the part's critical dimension with a high-resolution measuring instrument, often the best commercially available.

- The customer also makes measurements of the part's dimension, with a comparable or identical measuring instrument.

- The results of the manufacturer's measurements and of the customer's measurements are of high precision and high reproducibility.

- The results of the manufacturer's measurements indicate that the part dimension is within specified tolerance.

- In contrast, the results of the customer's measurements indicate that the part dimension is out of tolerance.

- To the manufacturer, the part conforms to specification and is acceptable.

- To the customer, the part fails to conform to specification and is unacceptable.

- The discrepancy in the measurement results cannot be accounted for by the manufacturer and the customer.

In sum, the situation is a market-transaction disagreement between sets of results of high-precision, highreproducibility measurements made with state-of-theart measuring instruments on parts with state-of the-arttolerances.

For NIST to contribute to the resolution of such disagreements requires that NIST fundamentally advance the state of the art of measurement science and technology. Prototypical results of NIST to resolve such discrepancies are its photomask linewidth Standard Reference Materials (SRMs) and its gear-form calibration services. 
Over the last two decades, NIST has developed a family of photomask linewidth standards covering a range of linewidths measured by optical [15] or scanning electron microscopes [28] from $30 \mu \mathrm{m}$ down to $0.25 \mu \mathrm{m}$. More recently, NIST has developed calibration services for the dimensions and geometrical forms of involute gears that are critical parts of transmission power trains of aircraft, heavy equipment, and automobiles [29].

The prototypical solution to the problem of systematic differences in measurement results of dimensions produced by different dimensional measuring instruments is calibration of the instruments against the same reference standard. The requirement for the standard is that its measurement uncertainty be much smaller than the discrepancies in question.

Historically, the uncertainty associated with gages or inspection machines is required to be factors of 4,5 , or even 10 times smaller than tolerances. In turn, the uncertainty associated with industry reference standards is required to be factors of 4 to 10 times smaller than gage or inspection machine uncertainty. Finally, the uncertainties of NIST dimensional standards are expected to be factors 4 to 10 times smaller yet again [30]. Thus the uncertainties of reference measurements or calibrated standards sought from NIST can be factors of 64 to even 1000 times smaller than state-of-the-art tolerances.

The ability of NIST to provide reference measurements at such levels of uncertainty requires developments beyond the current state of the art in each of three areas:

- the physical artifact to be calibrated;

- the measuring machine to do the calibration

- the theoretical model of the systematic errors in measurement results arising from the interaction of the artifact and the measuring machine in the calibration process.

In addition, the three developments need be tied together in a measurement procedure that includes innovative measurement algorithms and methods.

\subsubsection{The Artifact}

The innovative physical artifact that NIST needs to develop in order to provide reference measurements to deal with the scenario described above is one that mimics the product features for which industry is experiencing the discrepant measurement results. This artifact is required to be of a material and a form and have features and dimensions similar to the dimensioned part that is at issue in the industry. Because the artifact is used in two sets of measurements, variations in its dimensioned features contribute to a user measurement uncertainty twice: once in its calibration by NIST and once again in its use for calibration of a user's instrument. As a result, the variations in the features are required to be substantially smaller than the measurement uncertainty required of NIST. Ideally, variations in features would be so small as to contribute insignificantly to the measurement uncertainty NIST delivers. By the same token, these variations should be substantially smaller than the variations of the manufactured part in question. Since the product is the result of stateof-the-art manufacturing processes, the artifact often needs to be of a degree of geometric perfection beyond the current state of the art.

The historical prototype of the idealized-geometry physical artifact as the basis for low-uncertainty calibrations by NBS-NIST is the industrial precision gage block. Gage blocks were invented and developed by others between 1910 and 1920 and substantially improved by a NIST-industry collaboration in the $1950 \mathrm{~s}$ $[13,6]$. Modern counterparts to gage blocks are the NIST photomask linewidth standard [23], the NIST sinusoidal surface-roughness standard [31,32], and the NIST microelectronic overlay standard [33]. Each of these artifact standards, developed during the last two decades, required advancing the state-of-the-art of manufacturing processes for its production.

\subsubsection{The Measuring Machine}

For a NIST measurement process to be capable of resolving the discrepancies encountered by industry in its measurement processes, the NIST measurements need to be highly reproducible and free of the systematic errors implicit in industry's reproducible but discrepant results.

At the heart of each of NIST's industry-problemsolving measurement processes is an innovative, specialized, first-principles measuring machine. The innovative aspect of the machine is its ability to make measurements with uncertainty previously unattainable for that specific task. The specialized aspect of the machine is its ability to make task-specific measurements, such as that of photomask linewidth, gear involute, or machined-part cylindricity, over a particular range of feature dimension. The first-principles aspect of the machine is its direct realization of the definition of the SI unit of length in the task-specific dimensional measurement it is designed to perform. Practical realization of the definition of the meter (Sec. 1.1.1) in a dimensional measurement most commonly implies that one must be able to do three things:

- generate a line in space

- define the end points of that line

- divide the interval of space between the end points of that line into appropriate subintervals. 
To carry out these functions, a measuring machine needs to have certain essential elements [34].

\section{Frame}

The first element is the means for the physical definition of a line in space. Geometrically, a line is defined by a direction in space relative to a coordinate system having axes and an origin. The frame is the set of physical elements that define physical points, lines, and planes to embody, to the degree of perfection required, the ideal geometry of that reference coordinate system. In general, axes are generated by a variety of mechanical devices that constrain motion in all but one direction such as v-groove ways, while an origin is generated by a well-defined mechanical stop.

\section{Motion Generator}

The second element is a set of physical structures, such as a moving stage or an image scanner, to generate reproducible relative motion between the object of measurement and the coordinate frame. This motion may be actual or virtual. Actual motion is by means of a physical carriage that translates the object relative to a stationary frame or translates the frame relative to the stationary object. Virtual motion may be, for example, by means of translation of an image of the object relative to the coordinate frame.

\section{Probe}

The third element is a probe, that is a sensor system that simultaneously detects a boundary, such as an edge or surface, of the object to be measured and locates that detected feature relative to the coordinate system. The physical principles underlying probes on NIST firstprinciples dimensional measuring machines include: the mechanical-contact of a gage-block comparator, the reflected visible light of a linescale optical microscope, the scattered electrons of a metrology SEM and the quantum-mechanical tunneled electrons of an STM. In each case, the probe, in effect, defines the end points of the line segment implied in the "length of path" portion of the definition of the unit of length.

\section{Interval and Subintervals}

The last element is the means for determining an interval or subintervals of distance in terms of the definition of the meter. The means is to use the known wavelength of a reference laser and laser displacement interferometry. The reference laser is typically a commercial, frequency-stabilized, HeNe laser calibrated against an iodine-frequency-stabilized $\mathrm{HeNe}$ laser, one of the recommended radiations for the practical realization of the meter. Since the definition of the meter fixes the speed of light in vacuum to be exactly 299792458 meters per second, and the relation of the wavelength of an electromagnetic radiation to its frequency is $\lambda=c / v$, by measuring the frequency of a laser with a given relative uncertainty, one immediately knows its wavelength with the same relative uncertainty.

Table 2 describes the type of probe, frame, scales and length reference for each of six different dimensional measuring machines at NIST, each of which embodies the elements for the realization of the meter as the SI unit of length.

- The NIST coordinate measuring machine ${ }^{\circ} \mathrm{CMM}$ ) for measuring industrial gages uses a mechanicalcontact probe, an $x$ - $y$ slideways stage and $z$-axis ram, and helium-neon laser displacement interferometers for each axis [12].

Table 2. NIST dimensional measuring machines for first-principles measurements of dimensions

\begin{tabular}{|c|c|c|c|c|}
\hline Measuring machine & Probe & Frame & Scales & Wavelength reference \\
\hline $\mathrm{CMM}^{\mathrm{a}}$ & Mechanical contact & $\begin{array}{l}x-y \text { stage } \\
z \text {-ram }\end{array}$ & $x, y \& z$ interferometers & $\mathrm{HeNe}$ \\
\hline Gage-block interferometer & Visible light & Platen, bridge & $z$ (Michelson) interferometer & $\mathrm{HeNe}$ \\
\hline Overlay microscope & Visible light & $\begin{array}{l}x-y \text { stage } \\
z-\mathrm{PZT}\end{array}$ & $x, y \& z$ interferometers & $\mathrm{HeNe}$ \\
\hline Metrology SEM & Electron beam & $x-y$ stage & $x$ interferometer & $\mathrm{HeNe}$ \\
\hline Calibrated AFM & Atomic force & $\begin{array}{l}x-y \text { stage } \\
z-\mathrm{PZT}\end{array}$ & $\begin{array}{c}x \& y \text { interferometers } \\
z \text { interferometer-calibrated CG }\end{array}$ & $\mathrm{HeNe}$ \\
\hline M3 & Scanning tunneling & $\begin{array}{l}x-y \text { stage } \\
z-\mathrm{PZT}\end{array}$ & $\begin{array}{c}x \& y \text { interferometers } \\
z \text { interferometer-calibrated PZT }\end{array}$ & $\mathrm{HeNe}$ \\
\hline
\end{tabular}

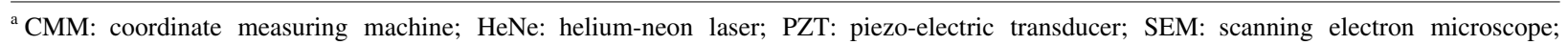
AFM: atomic force microscope; CG: capacitance gauge; M3: Molecular Measuring Machine. 
- The NIST gage block interferometer for calibration of precision gage blocks is a single $\mathrm{z}$-axis Michelson interferometer with a bridge over a fixed platen [22].

- The NIST overlay microscope, shown in Fig. 2, is a visible-light-microscope system with an $x-y$ stage with moveable $z$-axis, with helium-neon laser displacement interferometers on each axis for calibration of microelectronic overlay error standards [33].

- The NIST metrology SEMs are scanning electron microscopes with single-axis stage-interferometers system for calibrating $250 \mathrm{~nm}$ photomask linewidths [28] and high-accelerating-voltage SEM magnification standards [35].

- The NIST Calibrated Atomic Force Microscope (C-AFM) has laser displacement interferometers on each of its $x$ and $y$ axes and a laser-interferometer-calibrated capacitance gauge on its $z$ axis, for calibration of nanometer-scale step-height, pitch, and roughness standards [24].
- The NIST Molecular Measuring Machine (M3) is a scanning-tunneling-microscope-based system being developed for nanometer-uncertainty measurements over a $50 \mathrm{~mm}$ by $50 \mathrm{~mm}$ area [36].

\subsubsection{The Theoretical Model}

In addition to artifacts and measuring machines, NIST measurements to address industry's most fundamental measurement problems require theoretical models that advance the state-of-the-art. Such models are most often needed to scientifically understand the interaction between the artifact and measuring machine in order to eliminate systematic errors in measurement results due to that interaction. The source of the systematic error is in the physics that governs the interactions of the probe with the material boundary of the feature to be located. Probe-boundary interactions contribute to errors in length measurements depending upon the type of length being measured.

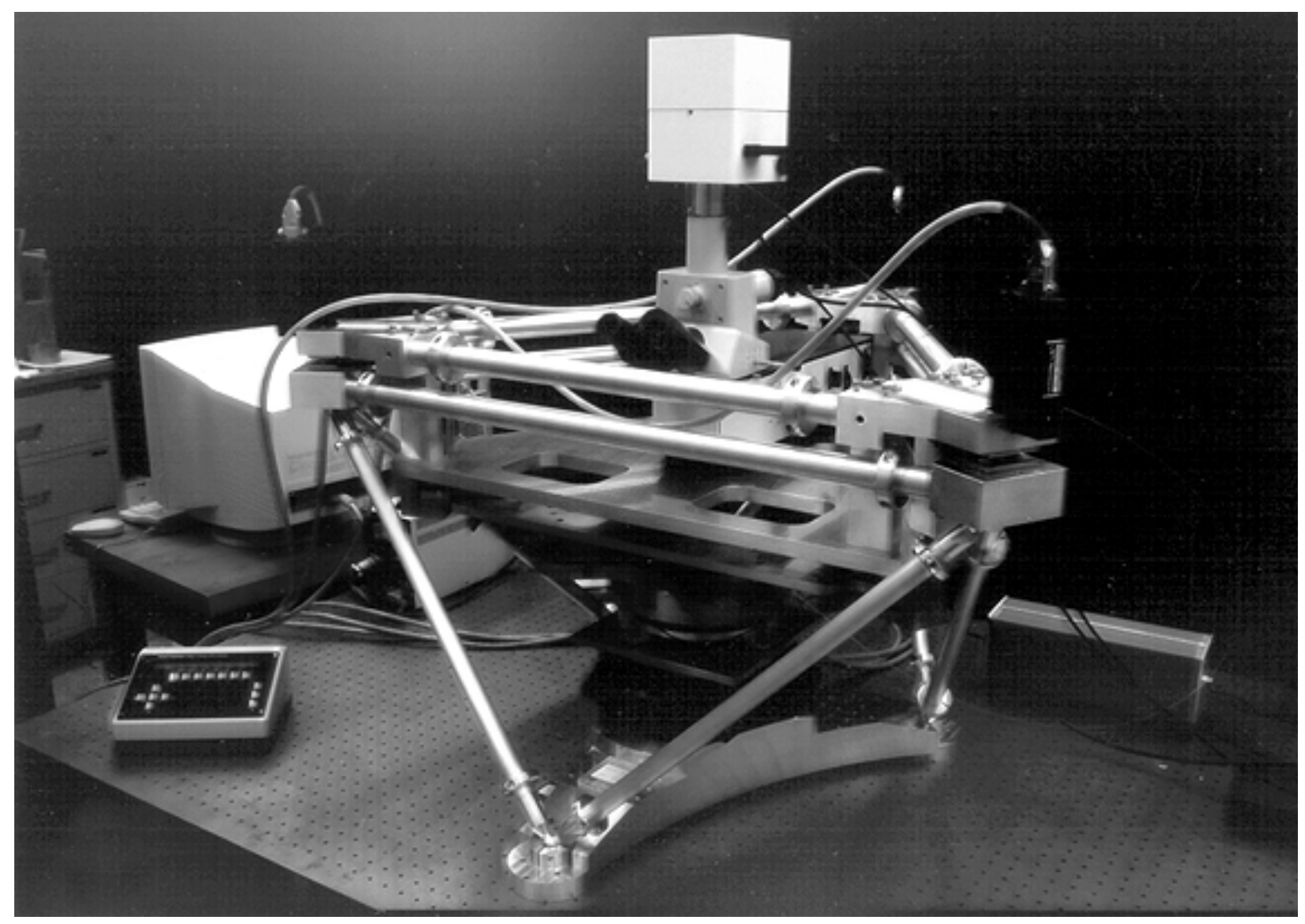

Fig. 2. The NIST optical overlay microscope, utilizing an innovative Stewart-platform structure and digital-array image processing [33] 
In dimensional metrology, there are four fundamental types of "lengths" [34]. Extension is the scalar quantity that describes the length of path in space between the locations of two opposite-facing boundaries of one object. Displacement is the vector quantity that describes the length of path in space between the locations of a single object at two different times. Position is the vector quantity that describes the length of path in space between the center of one object and an origin or coordinates equivalent to a second, reference object. Distance is the scalar quantity that describes the length of path in space between the centers of two objects. Each of the latter three types of length measurements is, in effect, the distance between either point-like or centroid-type features.

Extension-type measurements are most susceptible to probing errors and require the greatest degree of theoretical understanding in order for them to be carried out to low uncertainty. For displacement, position, and distance type measurements, probing errors at successive boundaries tend to be subtractive, canceling each other out. For extension-type measurements, probing errors at successive boundaries tend to be additive, reenforcing each other and creating systematic errors in resulting measurements. Automobile-engine cylinder bores, communication optical-fiber diameters, and microelectronic photomask linewidths are extensiontype measurements. For low-uncertainty measurement results to be achieved in such measurements, the systematic errors inherent to them must be identified, theoretically modeled, and removed.

Theoretical models developed by NIST to make low-uncertainty reference measurements have accounted for systematic errors in

- the interaction of the mechanical response of a class of commercial CMM stylus probe used in CMM measurements of calibration ball bars [37]

- interaction of visible light reflected from chromeon-glass lines in the optical-microscope measurement of the optical photomask linewidth [15]

- the emission of secondary electrons scattered from metal-on-silicon lines in the SEM measurement of the electron-beam and x-ray mask linewidths [28].

In addition, theoretical modeling has been developed to deal with systematic-error effects by

- group-theory-based estimation of finite dimensions and geometry of probes in scanned-probe-microscope measurements of surface morphology [38]

- Monte-Carlo simulation of the uncertainty of CMM measurements [39]
- a Bayesian-statistics method for calculation of measurement uncertainty using prior information [40]

- measurement uncertainty in the presence of uncorrected bias [41]

\subsubsection{The Measurement Algorithm}

Finally, state-of-the-art measurements require specialized measurement techniques, including measurement algorithms and procedures, to define the taskspecific measurement quantity, or measurand, of the measurement process. Current work has recently developed

- a methodology for calibrating high-resolution twodimensional grids [42]

- a technique for measuring interferometric phase shifts of gage blocks [22]

- a technique for low-uncertainty calibration of cylinder diameters [43]

- algorithms for calculating single-atom step heights [44]

- a method to determine linewidth based on counting the atom spacings across a line [45].

\subsubsection{Needs of Some Key Industries in Dimensional Metrology}

At present, the aircraft, automobile, computer, and microelectronic industries are representative of the industries that NIST work in dimensional metrology impacts.

\subsubsection{Aircraft Industry}

With the decline in defense spending world-wide and increasing global competition in the aircraft-aerospace industry, U.S. aerospace firms are looking to export markets for survival and growth. As a result, such firms see a need to adopt international specifications in order to achieve higher levels of demonstrable quality and performance standards and as a basis for sales and procurements and [46]. Tolerances are tightening in components and assemblies of the airframe and mechanical systems, with reduction in dimensional variability aimed to attain fits in fuselage assemblies without the historical practice of using shims [47]. These tighter tolerances include, for example, specifications of fastener-hole locations on a $35 \mathrm{~m}$ wing to $\pm 750 \mu \mathrm{m}\left(2 \times 10^{-5}\right)$ [48]. For comparison, Table 1 shows the expanded uncertainty $(k=2)$ for a NIST calibration of survey tapes at that distance, which is itself only $1 \times 10^{-5}$. 


\subsubsection{Automotive Industry}

With rapid globalization of the world's auto industry, international standards are altering the way business is conducted throughout the world [46]. With higher customer expectations for fit and function, automobile engines and drive trains now have the same micrometer dimensional tolerances associated with the finest mechanical-movement timepieces. Some representative tight tolerances in the automobile industry today include: $\pm 250 \mu \mathrm{m}$ assembly tolerances on $5 \mathrm{~m}$ luxuryclass automobile bodies; $\pm 7.5 \mu \mathrm{m}$ size tolerances on $96.5 \mathrm{~mm}$ engine piston bores; and $\pm 0.25 \mu \mathrm{m}$ gap tolerances on gasoline fuel-injectors [48]. To support such tolerances, the automobile industry and the measuring instrument manufacturing industry are seeking loweruncertainty standards in each of those areas.

\subsubsection{Computer Industry}

Hard-disk-drive technology, the pacesetter for the computer data storage industry, like electronics, is driven by competition to follow Moore's law in shrinking dimensions and tightening tolerances [49]. Hard disk drives are exhibiting a compound annual growth rate of $60 \%$ for areal information density, corresponding to decreases in dimensions and tolerances of $30 \%$ per year [50]. Today, hard disk drives involve design and fabrication of topographic structures of a few micrometers, lateral dimensions less than a micrometer, and film thicknesses of a few nanometers. The trend is for reduction of critical dimensions and tolerances on magnetic heads by a factor of 5 between 1997 and 2002 . In addition, over that same period, track widths are projected to decrease from $2 \mu \mathrm{m} \pm 0.2 \mu \mathrm{m}$ to $400 \mathrm{~nm} \pm$ $40 \mathrm{~nm}$ and pole-tip recessions from $5 \mathrm{~nm} \pm 0.5 \mathrm{~nm}$ to $1 \mathrm{~nm} \pm 0.1 \mathrm{~nm}[50]$.

\subsubsection{Microelectronics Industry}

For the electronics industry, the global economy means an environment more competitive than ever, with the key to United States success seen as the development of new, breakthrough technologies [46]. The historical trends for the key product areas of dynamic random access memory (DRAM) bit count and central processing unit (CPU) performance indicate continuing reduction in geometric dimensions. In accordance with Moore's law, minimum feature size is expected to decrease from $200 \mathrm{~nm}$ in 1997 to less than $100 \mathrm{~nm}$ after 2003. The National Technology Roadmap for Semiconductors, produced by the Semiconductor Industry
Association (SIA), seeks what it calls a three-standarddeviation control of $20 \mathrm{~nm}$ for gate critical dimensions for the current $250 \mathrm{~nm}$ generation of semiconductors and $10 \mathrm{~nm}$ for the $130 \mathrm{~nm}$ generation in the year 2003 [51]. For these two levels of control, SIA specifies three-standard-deviation metrology precisions of $4 \mathrm{~nm}$ and $2 \mathrm{~nm}$, respectively. Particularly challenging for the industry is the task of producing chips by the year 2006 with $100 \mathrm{~nm}$ features using non-optical lithography. Measurement is viewed as one of the five most difficult challenges it is facing [51].

\subsection{Current Work}

To address industry requirements such as those indicated above, NIST is carrying out a program of research and services at scales of dimensions from the macroscopic to the atomic.

\subsubsection{Large-Scale Coordinate Metrology}

The focus of this work is to develop methods and capabilities to support industries-including the aircraft, ship-building, construction-and-farm equipment, and automotive - that need to make measurements of sub-meter to multiple-meter parts and structures with low, well-characterized measurement uncertainties [52]. The creation and rise in the use of discrete-point coordinate measuring systems (CMS) poses an immense problem in ascertaining the uncertainty of measurement results associated with such systems. Part of the problem is due to the large sets of numerical coordinate positions that a CMS can produce as output compared to the simpler go/no-go indications of traditional gaging. Another part of the problem is the absence of standardized methods for the characterization of the measurement performance of a CMS. One aspect of NIST's approach to the problem is to develop computational models of the measurement uncertainty of CMSs, beginning with the older and more widely used type, the coordinate measuring machine (CMM). This work is addressing a selected set of CMMs, operated in favorable environments, measuring idealized parts. The other aspect of NIST's approach is to develop techniques for the characterization of the measurement performance of the newer, frameless type of CMS, such as theodolite and laser-tracker systems. Related to this work is research on absolute-distance interferometry using scanned-wavelength diodes, which allow pointand-measure determinations of distance without the requirement for uninterrupted beams as in single-wavelength displacement interferometry [53]. 


\subsubsection{Dilatometry}

The focus of this work is to develop a laboratory capability to measure the coefficient of thermal expansion (CTE) of materials of gages and prototype parts [52]. The goal is to support industry calibration and use of gages and artifacts at temperatures other than standard temperature. By international agreement, $20^{\circ} \mathrm{C}$ is the temperature, and the only temperature, at which length dimensions of manufactured parts are defined [54]. For a measurement made at a non-standard temperature, the length at $20^{\circ} \mathrm{C}$ must be calculated using the coefficients of thermal expansion of the particular gage and parts. In many cases, the uncertainties of factory measurements are limited by the uncertainty in the coefficient of thermal expansion of either the master gages or the part itself. Currently, there is no commercial or government calibration of CTEs of precision gages or parts available in the United States. NIST's approach is to (1) develop a dilatometer to allow the measurement of the CTE of virtually any material; and (2) explore the variability of the CTE in classes of materials, including different gage materials.

\subsubsection{Complex Form Metrology}

The focus of this work is to develop the capability to make low-uncertainty measurements of industrially important artifacts having regular geometrical forms other than the simple geometries of planes (gage blocks), cylinders (gage wires) and spheres (gage balls) [52]. NIST's approach is to apply the technique of substitute-geometry decomposition. In this approach, the complex geometry of a part is represented as being composed of the sum of simpler geometric elements; for example, an involute as being composed of a circle of a specific radius and an offset of a specific distance. Comparator measurements then made between master artifacts of the simple forms and the elements of the more complex part. Applied successfully to the less complex forms of ball-bar artifact standards and prototype helical gears, the technique is to be extended to the more complex forms of helical gears and threads.

\subsubsection{Microform Metrology}

The focus of this work is to develop the means to measure complex, 3D surface features at the micrometer scale that need to be quantified for their shape and size with measurement uncertainties compatible with tolerance requirements [52,55]. One of the requirements for microform metrology comes from U.S. and international work in Rockwell hardness standardization. Rockwell C hardness (HRC) is the most widely tested materials property for metal products. NIST's approach is to develop a microform calibration system using a stylus to measure dimensions, angles, profile deviations, and alignment errors, as well as surface roughness. The work is aimed at verifying the geometric correctness of the Rockwell indenters as an alternative to hardness performance comparisons. NIST standard indenters, combined with the use of the NIST standard testing machine and a standardized testing cycle, are being used to create, maintain, and reproduce the metrology-based Rockwell hardness scale in the United States and overcome any errors that might exist in the European Community's performance-based HRC scale [56].

\subsubsection{Surface Finish Metrology}

The focus of this work is to develop the capability to perform state-of-the-art measurements of the microtopography of surfaces, commonly referred to as the surface finish, a dimensional feature important to the function of a wide range of industrial products [52,57]. NIST's approach is to develop instrumentation, artifacts, and theoretical-statistical algorithms for the characterization of surface finishes using stylus profiling instruments, phase-measuring interference microscopes, and scanned probe microscopes. Issues being addressed include improved understanding of the differences between surface finish measurements performed using different types of instruments and the measurement of step-height calibrations using independently traceable techniques.

\subsubsection{Two-Dimensional Metrology}

The focus of this work is to develop measurement algorithms, data analyses techniques, and sensor metrology for micro- and nano-meter-uncertainty calibration and use of two-dimensional positional grids to support the microelectronics and related industries $[52,42]$. In the United States, the need for low uncertainty artifacts to test the machines is met partially by one-dimensional calibrations of line scales or single lines of grid plates. NIST's approach includes

- development of the measurement algorithm, method of data analysis, and sensor metrology needed to locate the grid position

- organization of an industry working group that can work towards a consensus industry standard for characterizing the measuring machines

- use by industry of a standard grid pattern, common measurement and data analysis procedures, 2D measurements on industry instruments, and NIST 1D measurements 
Prototypes of this standard grid have been made and circulated to industry laboratories to obtain a baseline estimate of the current industry capabilities. The eventual goal is to have a Standard Reference Material (SRM) gridplate that will be measured by industry under NIST direction, checked with a NIST measurement of some subset of grid points, and made available to industry.

\subsubsection{Optical Metrology}

The focus of this work is to develop the capability to perform state-of-the-art, optical-microscope-based dimensional measurements to address the measurement needs of industries that use optical-microscopes for measurement of microelectronic and related devices $[52,58]$. The measurements being made by industry include pitch (distance between similar-facing edges of successive graduations), linewidth (distance between opposite-facing edges of a single feature), and overlay (a hybrid feature associated with the mis-registration of successive planar levels on a microelectronic device). The NIST approach to advancing this field includes development of instrumentation, artifacts, and theoretical models of probe-artifact interactions affecting the uncertainty of measurements for confocal, reflection, and transmission optical microscopes operating with visible and UV light [58].

\subsubsection{SEM Metrology}

The focus of this work is to develop the capability to perform state-of-the-art, scanning-electron-microscope-based, dimensional measurements to address the measurement needs of industries that use SEMs for electron-beam-lithography fabrication and SEM-based measurement of microelectronic and related devices [52,59]. NIST's approach is to develop

- dimensional-metrology scanning-electron-microscope (SEM) instrumentation to allow low-uncertainty measurements directly traceable to the SI unit of length

- prototype calibration artifacts of appropriate materials and geometries

- Monte-Carlo simulations of the electron-beam and SEM-artifact interactions in measurements of linewidths as critical dimensions in microelectronic devices [59].

\subsubsection{Scanned Probe Microscope Metrology}

The focus of this work is to develop the capability to perform state-of-the-art, scanned probe microscope (SPM)-based, dimensional measurements to address the measurement needs of industries that use SPMs for fabrication and metrology in manufacturing and $R \& D$ [52]. SPMs include scanning tunneling microscopes (STMs) and atomic force microscopes (AFMs) with the former operating by means of quantum-mechanical tunneling of electrons and the latter by means of interatomic forces. Both sense the distance of its probe above a surface with sensitivities at nanometer-to-picometer levels of resolution. Accurate SPM measurements are particularly important to the semiconductor, data storage, and related microfabrication industries. The most common measurements performed by such SPM users are pitch (lateral feature separation), step height (vertical surface separation), critical dimension (feature width), and surface roughness (often specified using the root-mean-square roughness parameter). A calibrated AFM (C-AFM) has been developed to extend pitch measurements to sub-micrometer pitch values and below [24]. An STM-based "Molecular Measuring Machine" (M3) has been developed to make nanometerlevel measurements over a $50 \mathrm{~mm}$ by $50 \mathrm{~mm}$ area [36]. In addition, extensive work has been carried out on accounting for the effect of the finite size and geometry of the scanning tip in dimensional measurements made with SPMs $[38,60]$.

\subsubsection{Atom-Based Artifact Standards}

The focus of this work is to develop a family of dimensional artifact standards for which the dimensional properties of the artifact derive from atomic-scale material properties and, as a result, features have inherent nanometer- and sub-nanometer-scale dimensions and geometric perfection [52]. The relevant types of dimensional features of these atom-based artifact standards include counted-atom linewidths and lattice step heights. NIST's approach is to

- use atomic-scale material deposition processes and controlled surface modification to fabricate artifacts that have features with highly-controlled atomicscale dimensions based on the structure of the crystal lattice

- measure and statistically verify geometry and dimensions using metrology atomic-force and scanning-tunneling microscopes tied directly to the SI unit of length.

Target feature dimensions and uncertainties for these future atom-based standards are:

- linewidths of $300 \mathrm{~nm}$ and expanded uncertainty (coverage factor $k=2$ ) of $3 \mathrm{~nm}$

- step heights of $300 \mathrm{pm}$ and expanded uncertainty (coverage factor $k=2$ ) of $10 \mathrm{pm}$. 
Work in this area includes development of methods to determine linewidth based on counting of atom spacings across a line [61] and algorithms for calculating single-atom step heights [62].

\subsubsection{Atomic-Scale Displacement Metrology}

The focus of this work is to develop the laboratory capability to precisely generate and accurately measure displacements in increments of $50 \mathrm{pm}$ over distances of tens of centimeters. The intended result is improvement by an order of magnitude upon the approximate relative uncertainty of $5 \times 10^{-8}$ that forms the practical lower limit in long length measurements done using displacement interferometry in air. Such capability is to be based in part on advancing the state-of-the-art of displacement interferometry by a direct intercomparison of $\mathrm{x}$-ray, Fabry-Perot, and optical-heterodyne interferometry. In addition, it is to be based on long-range highprecision stages. These stages are to incorporate laserbased metrology; control of translation, pitch, and yaw, and positional capability commensurate with pm-level displacements. The resulting system of interferometry and stage will form the prototype for production and metrology stages of the future and is ultimately intended to be the basis of a next-generation linescale interferometer system for the measurement of linescales of lengths from less than $1 \mu \mathrm{m}$ to $1 \mathrm{~m}$ [63].

\section{The Future}

The future of length and dimensional metrology is being shaped by theoretical and practical limits to attainable uncertainties in measurement, by continuing trends in industry, and by the emerging response of NIST as an institution to those limits and trends.

\subsection{Limits: Ultimate, Standards-Based, and Practical}

There are two sources of pressure for the achievement of ever-smaller uncertainties in length and dimensional measurements. These are, first, the continuing industrial trend to tighter tolerances-represented in the microelectronics domain by Moore's Law-and, second, the continuing scientific trend to explore the limits of understanding through physical measurement. Given these drivers, a question that arises is whether there are theoretical and practical limits to the lowest uncertainty that may be achieved. The following sections discuss such lower limits-ultimate-theoretical, standards-based, and practical.

\subsubsection{Ultimate Theoretical Limits}

With the continuing evolution of technology, fundamental physics may impose limits on the uncertainty of measurements of length. At the forefront of today's experimental research in cosmology, quantum physics, relativity, and fundamental particles the question of ultimate theoretical limits is an immediate one.

\subsubsection{Quantization of Space}

The space of virtually all of current applied physics, engineering, and, hence, commerce is the space of Newtonian and relativistic mechanics. At this macroscopic level, space is a homogeneous continuum and no structure of space poses a lower limit to uncertainty of measurements of length. At the microscopic level, however, such may not be the case. Quantum effects become important and both gravity and the structure of space itself may be quantized. Much work is underway in the science community to explore these possibilities, which are expected to occur at dimensions of the order of the Planck length, $10^{-35} \mathrm{~m}$ [64].

\subsubsection{Heisenberg Uncertainty Principle}

The Heisenberg uncertainty principle (HUP) does not place an ultimate limit on the uncertainty of measurement of position per se. However, it does set an ultimate limit on the simultaneous, and successive, measurements of special pairs of measurement quantities, one of which includes position [65]. According to the HUP, a measurement of the momentum of an object must disturb its position and a measurement of its position must disturb its momentum. The result is that the more accurately that momentum is known, the less accurately can its position be known. The HUP limit is given by

$$
\Delta x \times \Delta p \geq \hbar / 2,
$$

where $\Delta x$ is the uncertainty in position, $\Delta p$ is the uncertainty in momentum, and $\hbar$ is the Planck constant divided by $2 \pi$. The effect of the HUP limit was encountered in efforts to detect cosmic gravitational waves. In that experiment, measurements of the change in position as small as $10^{-21} \mathrm{~m}$ of detectors weighing up to 10 metric tons needed to be made at time intervals of $\tau=10^{-3} \mathrm{~s}$. For these conditions, the HUP set a limit in the uncertainty in successive measurements of position of $\Delta x$ approximately $5 \times 10^{-21} \mathrm{~m}$, five times worse than that desired [66]. 


\subsubsection{Johnson $k T$ Noise}

There is a dimensional equivalent of Johnson, or thermal, noise that places an ultimate limit on the uncertainty of measurement of dimensional features [67]. Johnson noise in an electronic circuit is the variation in the voltage across a conductor due to thermal agitation of the electrons passing through it [68]. This Johnson noise is proportional to $(R k T)^{1 / 2}$ where $R$ is the resistance, $k$ is the Boltzmann constant and $T$ is the thermodynamic temperature. Thermal length fluctuations of a solid, the spatial equivalent of electronic Johnson noise, are due to thermal agitation of the atoms of the material. In a measuring machine, such thermal noise places an ultimate limit on the location of the origin of the axes of the machine and, therefore, on the uncertainty of position measurements the machine can attain. Thermal noise similarly limits the uncertainty with which the length of an object can be measured. For example, for a homogenous isotropic cube, the root-mean-square (rms) thermal fluctuation $\Delta l$ in the length $l$ of the side of the cube is given by

$$
\Delta l=(k T / 3 B l)^{1 / 2},
$$

where $B$ is the bulk modulus of the material of the cube. Note that this contribution to the uncertainty in the measurement of the length of a material object is inversely proportional to the length and thus becomes more and more important at smaller and smaller scales. For example, for an object with a bulk modulus of that of fused silica, $3.5 \times 10^{10} \mathrm{~N} / \mathrm{m}^{2}$, and a temperature of $300 \mathrm{~K}$, the rms fluctuation in dimension of a $1 \mathrm{~m}$ cube is $0.2 \mathrm{fm}\left(10^{-15} \mathrm{~m}\right)$ or, fractionally, $2 \times 10^{-16}$. The rms fluctuation in a $1 \mathrm{~nm}$ cube is $6.3 \mathrm{pm}\left(10^{-12} \mathrm{~m}\right)$, fractionally $6 \times 10^{-3}$ or $0.6 \%$ [67].

\subsubsection{Limits from Primary Reference Standards}

Two other reference standards for SI units place ultimate limits on the uncertainty with which measurements of length can be made. These are the reference standards for the practical realization of the second as the unit of time and for the kelvin as the unit of temperature.

\subsubsection{Primary Reference Standard for the Second and for the Meter}

While an independent unit, the meter, the SI base unit of length, is now defined in terms of the speed of light in vacuum and an interval of time. As a result, a limit for uncertainty of measurements of length in principle is set by the uncertainty with which the second, the SI base unit of time, can be realized. The primary standard for interval of time is an array of atomic clocks located at national metrology institutes and the International Bureau of Weights and Measures (BIPM). The current relative standard uncertainty associated with the timescale based on this array of atomic clocks is 1.5 to $5 \times 10^{-15}$ [69]. The uncertainty of the NIST cesium primary frequency standard is estimated to be $1.8 \times 10^{-15}[70]$. However, the de facto primary-standard limit for practical SI-unit measurements of length is not the cesium atomic clock itself, but another frequency standard referenced to that clock, the iodine-stabilized helium-neon laser. The current relative standard uncertainty for the $632.99 \mathrm{~nm}$ line of an iodine-stabilized helium-neon laser, the work-horse reference standard for practical metrology that conforms to the CIPM prescription for design and operation, is $2.5 \times 10^{-11}$ [4].

\subsubsection{Temperature Standards and Length of Material Objects}

Materials expand and contract with changes in temperature. However, by international agreement, the reference temperature at which the length of a material object is defined is $20^{\circ} \mathrm{C}$. As a result, the uncertainty with which the International Temperature Scale for 1990, ITS-90, can be implemented at $20^{\circ} \mathrm{C}$ sets another primary-standard limit for uncertainty of measurements of material length. The current reproducibility of ITS-90 at the length-standard reference temperature of $20{ }^{\circ} \mathrm{C}$ is $0.0001{ }^{\circ} \mathrm{C}$. Given that the change in length $\Delta L$ of a material object of length $L$ with coefficient of thermal expansion $\alpha$ at $t=20^{\circ} \mathrm{C}$ for a change in temperature $\Delta t$ is given by:

$$
\Delta L / L=\alpha \cdot \Delta t,
$$

then the current thermal limit for determination of the length of a material at the reference temperature of $20{ }^{\circ} \mathrm{C}$ with a coefficient of thermal expansion in the range from 2.5 to $25 \times 10^{-6} /{ }^{\circ} \mathrm{C}$, corresponding approximately to silicon and aluminum, is fractionally $2.5 \times 10^{-10}$ and $2.5 \times 10^{-9}$, respectively. As such, in terms of relative expanded uncertainty (coverage factor $k=2$ ), the current temperature-defined limit for the determination of the length of a body of common materials is of the order of $5 \times 10^{-10}$ [71].

\subsubsection{Practical Limits}

Away from the strictly controlled laboratory conditions of national metrology institutes, where measurements of spatial quantities are made at world state-ofthe-art capability, measurement uncertainties are more often determined by practical, rather than ultimate, limits. 


\subsubsection{Displacement Interferometry}

Optical-wavelength displacement interferometry, which forms the practical basis for SI-based measure ments of length, is limited in practice by variations in the index of refraction of the medium, typically air, through which the laser light beam propagates in the course of the measurement. Since the index of refraction of a gas is a function of its temperature, pressure, humidity, and chemical composition, the uncertainty for optical interferometric displacement measurements made without compensation for actual variations in those parameters can be large. For example, a fractional length error of $1 \times 10^{-6}$ would result from any one of the following variations: a $1{ }^{\circ} \mathrm{C}$ change in temperature, a $0.33 \mathrm{kPa}(2.5 \mathrm{~mm} \mathrm{Hg})$ change in atmospheric pressure, or an $80 \%$ change in relative humidity [72]. Using the Edlen formula (an internationally agreed upon equation for the calculation of the index of refraction of typical laboratory air as a function of wavelength, air temperature, air pressure, and relative humidity), compensation can be made for these variations. As a result, a practical lower limit for the fractional uncertainty of laser displacement measurements is estimated to be $1.2 \times 10^{-7}$. The fractional uncertainty in the Edlen formula itself is estimated to be $5 \times 10^{-8}$, which forms the practical lower limit of long length measurements done using displacement interferometry in air [72]. For short lengths, the practical combined-standard-uncertainty limit of optical heterodyne interferometry, whether in air or vacuum, due to all factors (including internal reflections, mixing of polarization states, and diffraction), has been estimated to be $0.1 \mathrm{~nm}$ [67].

\subsubsection{Probe Limitations}

Probing as the means to detect the boundary of an object places practical limits on uncertainty attainable in dimensional measurements. One source of this uncertainty is uncompensated variations in the effective location of the probe as it interacts with the object boundary. For a dimensional measurement, probing of two successive boundaries is required. For a measurement of displacement, distance, or position, some of the systematic errors of probing of the successive boundaries are subtractive, cancel out, and do not contribute to the measurement uncertainty. For a measurement of an extension, some of these same systematic errors are additiv and increase the overall error or uncertainty of measurement. Table 3 shows representative uncertainties in measurements of feature spacings and widths due to probe-object interactions with progressively higher resolution probes, including mechanicalcontact coordinate measuring machines [34] and optical, scanning electron, and scanning tunneling microscopes [67].

\subsubsection{Temperature}

The dependence of the length of a material body on temperature is such an important effect in industrial length metrology that temperature uncertainty is very often the practical limiter of uncertainty.

Table 4 shows length measurement uncertainties associated with the limiting uncertainties attainable with state-of-the-art temperature measurement by different types of thermometry for a material with an assumed

Table 3. Representative combined standard uncertainties in measurements of feature spacings and widths due to probe-object interactions (coverage factor $k=2$ assumed) [34,67]

\begin{tabular}{cccc}
\hline \hline \multicolumn{1}{c}{ Type of probe } & Probe-object interaction & Uncertainty in feature spacing & Uncertainty in feature width \\
\hline Mechanical-contact CMM & Mechanical deformation & $0.2 \mu \mathrm{m}$ & $0.5 \mu \mathrm{m}$ \\
Optical microscope (OM) & Optical diffraction & $0.045 \mu \mathrm{m}$ & $0.065 \mu \mathrm{m}$ to $0.65 \mu \mathrm{m}$ \\
Scanning electron microscope (SEM) & Electron scattering & $4 \mathrm{~nm}$ & $6 \mathrm{~nm}$ to $60 \mathrm{~nm}$ \\
Scanning tunneling microscope (STM) & Quantum vacuum tunneling & $0.014 \mathrm{~nm}$ & $0.15 \mathrm{~nm}$ to $0.2 \mathrm{~nm}$ \\
\hline
\end{tabular}

${ }^{\mathrm{a}}$ Coordinate measuring machine.

Table 4. Lenght measurement uncertainties associated with the limiting standard uncertainties of temperature measurement by different forms of thermometry (coverage factor $k=1$ )

\begin{tabular}{ccccc}
\hline \hline Sensor element $^{\mathrm{a}}$ & Reference element & Reference instrument & Temperature uncertainty & Length uncertainty at $1 \mathrm{~m}$ for steel \\
\hline SPRT & Ga-Pt & & $0.0001{ }^{\circ} \mathrm{C}$ & $1 \mathrm{~nm}$ \\
SPRT & SPRT & Bridge & $0.001{ }^{\circ} \mathrm{C}$ & $10 \mathrm{~nm}$ \\
TC & SPRT & Bridge & $0.002{ }^{\circ} \mathrm{C}$ & $20 \mathrm{~nm}$ \\
Thermistor & & Bridge & $0.01{ }^{\circ} \mathrm{C}$ & $0.1 \mu \mathrm{m}$ \\
Hg & & $0.03{ }^{\circ} \mathrm{C}$ & $0.3 \mu \mathrm{m}$ \\
TC & & $0.1{ }^{\circ} \mathrm{C}$ & $1 \mu \mathrm{m}$ \\
\hline
\end{tabular}

${ }^{\text {a }}$ SPRT: Standard platinum resistance thermometer; TC: thermocouple; Hg: mercury-in-glass thermometer; DVM: digital volt meter. 
coefficient of thermal expansion of $10 \times 10^{-6} /{ }^{\circ} \mathrm{C}$, which corresponds approximately to that of steel. These types of thermometry are [71]

- a standard platinum resistance thermometer (SPRT) immersed in a gallium melting-point cell

- and SPRT as a sensor referenced to another primary-calibrated SPRT via a resistance bridge

- a thermocouple (TC) referenced to an SPRT by a bridge

- a thermistor

- a mercury(Hg)-in-glass thermometer

- a thermocouple.

Table 5 shows the standard uncertainties and relative standard uncertainties, $u(L)$ and $u_{\mathrm{r}}=u(L) / L$, for representative laboratory and industrial measurements of length $L$ with different degrees of temperature control and nearness to standard temperature. The uncertainties correspond to realistic limiting conditions of measurement in industrial and standards-laboratory applications [71]. For such measurements, there are two contributions to the overall uncertainty $u(L)$ in a measured material length. First, there is the contribution due to the variation in temperature, which is proportional to the coefficient of thermal expansion $\alpha$ and the uncertainty in the temperature $u(t)$. Second, there is the contribution due to the uncertainty in the value of the thermal expansion, which is proportional to the uncertainty in the coefficient of thermal expansion $\mathrm{u}(\alpha)$ and the difference, $t-20{ }^{\circ} \mathrm{C}$, between the actual temperature $t$ and the standard temperature $t_{0}$. When combined in quadrature, the overall combined standard uncertainty in length measurements made at a non-standard temperature is given by:

$$
u(L)=L \cdot\left[\{\alpha \cdot u(t)\}^{2}+\left\{u(\alpha) \cdot\left(t-20^{\circ} \mathrm{C}\right)\right\}^{2}\right]^{1 / 2} .
$$

The second and third columns show representative practical limits of length measurement uncertainties due to temperature associated, for example, with the manufacture of a high-quality, aluminum automobile-engine piston and a steel precision lead screw under the conditions specified. Corresponding uncertainties in distance measurements under conditions representative of tertiary, secondary, and primary length-standards laboratories are shown in columns three, four and five. The last column in the table shows aspects of a nmuncertainty measuring machine currently under development [36]. Achievement of a combined standard uncertainty of $1 \mathrm{~nm}$ in measurement of a distance of $70 \mathrm{~mm}$ on a silicon substrate with no more than $0.1 \mathrm{~nm}$ contributed by thermal effects requires a temperature uncertainty and an average temperature difference from standard temperature of less than of $0.001{ }^{\circ} \mathrm{C}$ [36].

\subsection{Industry Trends and Emerging NIST Responses}

According to one set of manufacturing industry watchers [46], the highest-level macroscopic trends expected to dominate the opening of the 21 st century are

- the globalization of markets and business competition

- the accelerating pace of change in technology

- the rapidly expanding access to technology

- the ubiquitous availability and distribution of information

- the increase of customer expectations

Coupled to these highest-level trends are two strong intermediate-level trends expected to affect the areas of concern of this article: a further Moore's-Law-like tightening of tolerances on manufactured products and a shift to greater emphasis on international industry

Table 5. Length measurement uncertainties associated with different degrees of temperature measurement and control attainable in principle at temperatures near but not exactly at the standard temperature $t_{0}$ of $20^{\circ} \mathrm{C}$

\begin{tabular}{|c|c|c|c|c|c|c|}
\hline & Engine piston & Lead screw & Tertiary laboratory & Secondary laboratory & Primary laboratory & $\mathrm{R} \& \mathrm{D}$ device \\
\hline$L$ & $100 \mathrm{~mm}$ & $1000 \mathrm{~mm}$ & $1000 \mathrm{~mm}$ & $1000 \mathrm{~m}$ & $1000 \mathrm{~mm}$ & $70 \mathrm{~mm}$ \\
\hline Material & Aluminum & Steel & Steel & Steel & Steel & $\mathrm{Si}$ \\
\hline$\alpha\left(10^{-6} /{ }^{\circ} \mathrm{C}\right)$ & 23.4 & 11.8 & 11.8 & 11.8 & 11.8 & 2.6 \\
\hline$u(t)$ & $10^{\circ} \mathrm{C}$ & $1{ }^{\circ} \mathrm{C}$ & $0.1^{\circ} \mathrm{C}$ & $0.01{ }^{\circ} \mathrm{C}$ & $0.001^{\circ} \mathrm{C}$ & $0.001{ }^{\circ} \mathrm{C}$ \\
\hline$u(\alpha)\left(10^{-6} /{ }^{\circ} \mathrm{C}\right)$ & 0.7 & 0.7 & 0.035 & 0.035 & 0.035 & \\
\hline$t-t_{0}$ & $3{ }^{\circ} \mathrm{C}$ & $3{ }^{\circ} \mathrm{C}$ & $1^{\circ} \mathrm{C}$ & $0.1{ }^{\circ} \mathrm{C}$ & $0.01{ }^{\circ} \mathrm{C}$ & $0.000{ }^{\circ} \mathrm{C}$ \\
\hline$u(L) / L$ & $2.3 \times 10^{-4}$ & $1.2 \times 10^{-5}$ & $1.2 \times 10^{-6}$ & $1.2 \times 10^{-7}$ & $1.2 \times 10^{-8}$ & $2.6 \times 10^{-9}$ \\
\hline$u(L)$ & $23 \mu \mathrm{m}$ & $12 \mu \mathrm{m}$ & $1.2 \mu \mathrm{m}$ & $0.12 \mu \mathrm{m}$ & $12 \mathrm{~nm}$ & $0.2 \mathrm{~nm}$ \\
\hline
\end{tabular}


standards (over national industry standards). Three lower-level trends are specifically expected to shape the research, measurement services, and standards-commit tee activities of NIST in the area of length and dimensional measurements in the immediate future. These are emergence of new technologies, increased demand for calibration artifacts, and development of the ISO Global Product Specification chain of standards [52].

\subsubsection{Emergence of New Traceability}

Historically in the United States, traceability-the "old traceability"- -was driven virtually exclusively by defense procurement and regulatory safety requirements and could be satisfied in a pro forma manner. Currently, traceability-the "new traceability"-is being driven by commercial markets and is being specified in international product standards aimed to be more than pro forma in nature. This new traceability is a requirement that a buyer of dimensioned parts imposes on the manufacturer of those parts, either directly through a part specification or indirectly through a quality-management specification. The condition is that measurements on manufactured parts made to show conformity of part dimensions to buyer's specifications must be traceable. To exhibit the new traceability, measurement must be referenced to the international standard of length through a well-documented and unbroken chain of timely [73] task-specific [74] comparisons. Both the results of measurements and the uncertainties of the measurement results need to be shown for each comparison in the chain [27].

\subsubsection{Increasing Demand for Calibrated Artifacts}

Coupled to the accelerating rate of change of technology and to the new traceability requirements in international standards is U.S. industry need for new and improved, physical-artifact, dimensional standards applicable to industry-specific requirements. Two motivators for lower-uncertainty artifact standards are commonly cited by U.S. manufacturing companies. First, there is a need for traceability to meet ISO-9000type quality requirements for products to be sold both in the European Economic Community and in the Pacificrim nations. Second, there is a need for low-uncertainty references to support development of innovative, hightechnology products comparable to those developed by Japan [75].

\subsubsection{Development of GPS Chain of Standards}

Coupled with the trend toward globalization of markets and the rise of international over national industry standards is development of an all-encompass- ing set of ISO Standards on "Geometric Product Specifications (GPS)" [74]. This family of standards deals in detail with verifying that measurements made on a manufactured part insure conformity of the part to design specification. The GPS standards cover all of dimensional features indicated on a technical drawing, such as size, distance, position and surface roughness, and all related measuring instruments and their calibration. It is the GPS that requires that results of dimensional measurements made on a manufactured part have an associated uncertainty specific to the type of part feature measured in a particular way ("task-specific") and be traceable to the international standard of length [76].

\subsection{The Evolving NIST Response}

To meet anticipated needs of U.S. manufacturing industries, NIST is undertaking alternatives to the traditional NMI as the top of a classical hierarchy of calibrations.

\subsubsection{Atom-Based Artifact Standards}

As an alternative to traditional artifact standards, NIST is seeking to do for nano-scale dimensional metrology what the redefinition of the meter did for length, allow a move from man-made prototype standards to constants of nature as intrinsic standards. Historically, precision artifact standards-from gage blocks to photomask linewidths-have received their form by material-shaping manufacturing processes and received their dimensional values by an independent calibration. The objective of this future-oriented work is to achieve a family of dimensional standards that receive their form and dimensions from the atomic lattice $[44,45]$. Figure 3 shows the first prototype of such a standard, one in which the atom-spacing of the Si (111) lattice provides the form and dimension of a step height standard [24].

\subsubsection{Use of Other Government Capabilities}

In one case, an alternative to NIST's use of its own equipment and staff as the sole basis for NIST dimensional-measurement calibration services, NIST is using those of another Federal agency. NIST now provides calibrations of industrial step gages using equipment and staff of the Department of Energy's governmentowned, contractor-operated Y12 facility in Oak Ridge, Tennessee, under the administrative and metrological control of NIST. In addition, NIST is metrologically supporting that facility's own provision of NIST-traceable calibrations in gear form and other dimensional quantities. It does so through its collaboration in the 


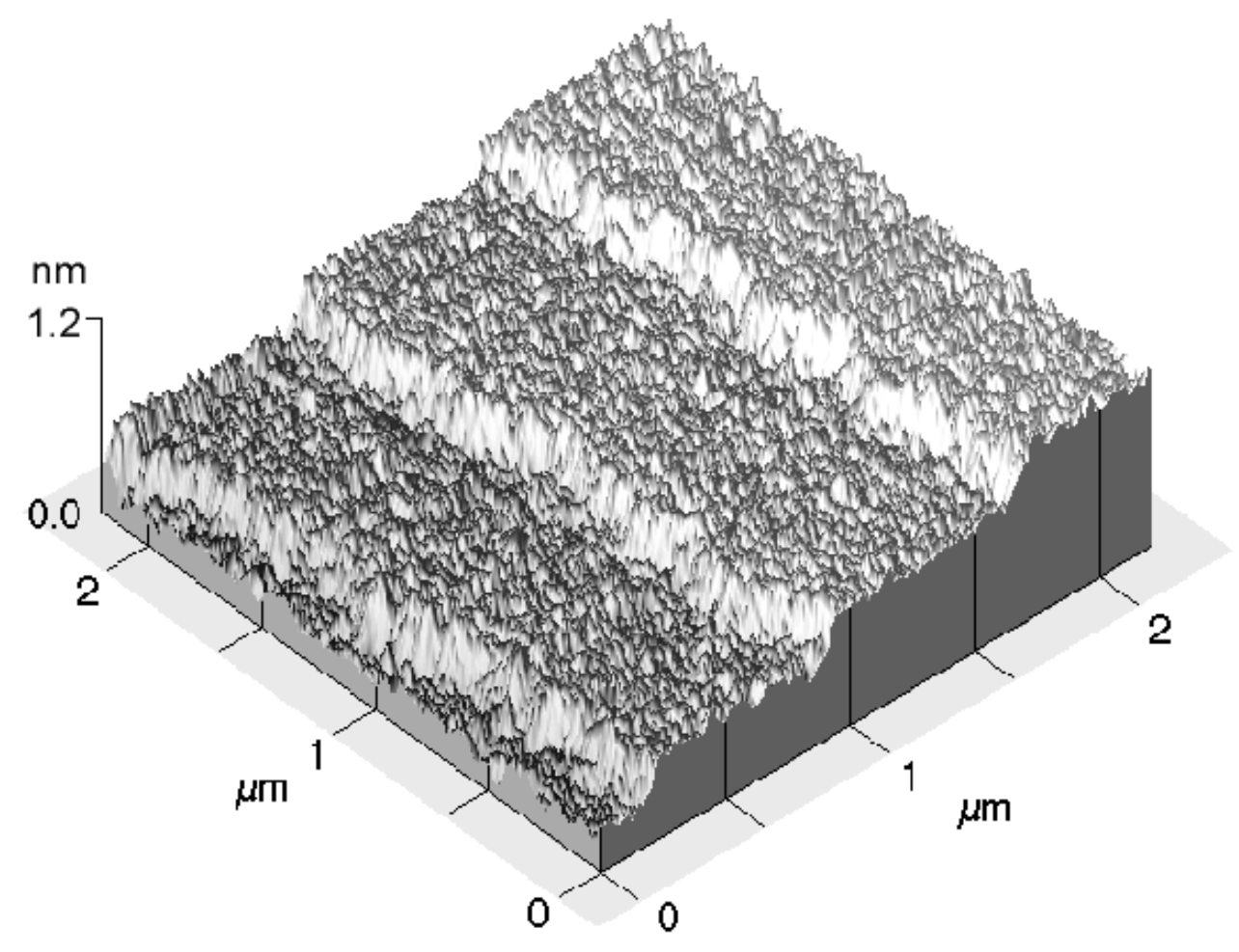

Fig. 3. NIST calibrated atomic force microscope (C-AFM) image of single-atom step heights on a silicon (111) lattice [24].

joint NIST-DoE/Y12 Metrology Center at Y12. This overall endeavor has been honored with two U.S. Vice President's Hammer Awards for overcoming institutional barriers to excellence in provision of customer service, one in each of the two areas of collaboration [77].

\subsubsection{Use of Industry Capabilities}

As one alternative to development of a NIST Standard Reference Material and acquisition of multimillion-dollar measuring machines, NIST has initiated industry efforts to achieve NIST-traceable calibrations of next-generation 2D grids for the microelectronics industry without NIST calibration of 2D grids. It has done so by a combination of actions [42]. First, it led the formation of a standards committee to define a standardized pattern for a 2D grid standard. Then it organized an industry working group to agree upon the design and procedures for measurement and data analysis procedures for a $2 \mathrm{D}$ grid standard. It arranged use of industry equipment for measurements of the 2D grid. And, finally, it performed 1D measurements to provide the link to the SI unit of length.

\subsubsection{Shop Floor as NMI}

Finally, NIST is pursuing an alternative to its development of task-specific measurement services, capabil- ities, and methods. NIST has initiated a program of research and standards-committee activities to support industry's ability to carry out task-specific dimensional measurements without recourse to NIST calibrated dimensional standards. For such to be the case, industry needs standardized means to carry out dimensional measurements on the manufacturing shop floor that

- are directly and immediately traceable to the SI unit of length

- have uncertainty statements that comply with the ISO "Guide to the Expression of Uncertainty in Measurement"

- are able to satisfy the requirements of the emerging ISO GPS chain of standards

- are able to satisfy the quality system requirements of ISO 9000, ISO 17025, and NCSL Z540-1

all without recourse to NMI-calibrated dimensional standards [78]. NIST's approach is to carry out R\&D on non-task-specific measurement techniques and support development by industry of documentary standards, which taken together would allow industry to meet the conditions above without the need for NIST taskspecific reference standards. 


\section{Conclusion}

This paper has discussed the past, present, and future of length and dimensional measurements at NIST. It has examined the evolution of the SI unit of length through its three definitions, including the contributions of NIST to the redefinitions through work on mercury-198 pressure lamps and iodine-stabilized helium-neon lasers as reference wavelength standards. It has also examined the evolution of dimensional metrology since 1901, including the contributions of NIST in that field. NIST's historical achievements include its work on precision gage blocks, software-error correction of coordinate measuring machines, optical and SEM photomask linewidth standards, and the first scannedprobe microscope (the basis for the Nobel-Prizewinning scanning tunneling microscope). Current work the paper describes includes a broad range of measurement technologies from 100-meter-range laser-trackers to picometer-resolution displacement interferometers. Finally, it has looked at trends for the future. These trends suggest that the first decade of the second century for NIST may be governed by a search for alternative ways to meet the challenging technological needs of the United States for NIST measurement services.

\section{References}

[1] BIPM, The BIPM and the evolution of the definition of the meter, BIPM, www.bipm.fr/enus/3_SI/metre.hist.html, Sevres France (1998).

[2] CIPM, New definition of the meter: the wavelength of krypton86, Proc. 11th General Council of Weights and Measures, Paris France (1960).

[3] Documents concerning the new definition of the meter, Metrologia 19, 163-177 (1984).

[4] T. J. Quinn, Practical realization of the definition of the metre, Metrologia 36 (3), 211-244 (1997).

[5] T. Doiron, Analysis of NBS records of early linescale calibrations relative to the U.S. prototype meter, Private communication, NIST, Gaithersburg MD 20899 (1999).

[6] E. Passaglia and K. Beal, A Unique Institution: The National Bureau of Standards 1950-1969, U.S. Government Printing Office, Washington DC (1999) p. 346.

[7] W. Schweitzer, E. Kessler, R. Deslattes, H. Layer, and J. Whetstone, Description, performance and wavelengths of iodine stabilized lasers, Appl. Opt. 12 (1), 2927-2938 (1973).

[8] H. Layer, R. Deslattes, and W. Schweitzer, Laser wavelength comparison by high resolution interferometry, Appl. Opt. 15 (3), 734-743 (1976).

[9] H. Layer, A portable iodine stabilized helium-neon laser, IEEE Trans. Instrum. Meas. 29, 4 (1980).

[10] D. Jennings, C. Pollock, F. Peterson, K. Evenson, J. Wells, J. Hall, and H. Layer, Direct frequency measurements of the I2-stabilized He-Ne 473-THz (633-nm) Laser, Opt. Lett. 8 (3), 136-138 (1983).
[11] J. Beers and W. Penzes, The NIST length scale interferometer, J. Res. Natl. Inst. Stand. Technol. 104 (3), 225-252 (1999).

[12] T. Doiron and J. Stoup, Uncertainty and dimensional calibrations, J. Res. Natl. Inst. Stand. Technol. 102 (6), 647-676 (1997).

[13] C. Peters and H. Boyd, Interference methods for standardizing and testing precision gage blocks, Scientific Papers of the Bureau of Standards 17, No. 436, 677-713 (1922).

[14] R. Young, The Topografiner: an instrument for measuring surface microtopography, Rev. Sci. Instr. 43 (7), 999-1011 (1972).

[15] D. Nyyssonen and R. Larrabee, Submicrometer linewidth metrology in the optical microscope, Natl. Inst. Stand. Technol. 92 (3), 187-204 (1987).

[16] R. Hocken, J. Simpson, B. Borchardt, J. Lazar, C. Reeve, and P. Stein, Three-dimensional metrology, Annals CIRP 26, 403408 (1977).

[17] S. Jensen, G. Hembree, J. Marciando, and D. Swyt, Quantitative sub-micrometer linewidth determination using electron microscopy, SPIE 275, 100-108 (1981).

[18] T. Hamilton, Gages, Gaging and Inspection, Industrial Press, New York (1918) p. 52.

[19] N. Taniguchi, Current status and future trends of ultra-precision machining and ultra-fine materials processing, Annals CIRP 2, 2-5 (1983).

[20] R. Silver and J. Land, Benchmarking the length measurement capabilities of the National Institute of Standards and Technology, NISTIR 6036, Natl. Inst. Stand. Technol. (1998).

[21] T. Doiron, Reports of NIST calibrations of CMM step gages, NIST, Gaithersburg MD 20899 (1999).

[22] J. Stoup, B. Faust, and T. Doiron, A new technique for measuring interferometric phase shifts of gage blocks, Proc. Meas. Sci. Conf., Pasadena CA (1997).

[23] J. Potzick, Anti-reflecting-chromium linewidth standard SRM 473 for calibration of optical microscope linewidth measuring systems, NIST SP-260-129, Natl. Inst. Stand. Technol. (1997).

[24] R. Dixson, R. Köning, V. Tsai, J. Fu, and T. Vorburger, Dimensional metrology with the NIST calibrated atomic force microscope, Proc. SPIE 3677, 20 (1999).

[25] T. Vorburger, Reports of NIST surface calibrations and special tests, NIST, Gaithersburg MD 20899 (2000).

[26] D. Swyt, Challenges to NIST: the impact of tightening tolerances in the U.S. discrete-parts manufacturing industry, NISTIR 4757, Natl. Inst. Stand. Technol., Jan. 1992.

[27] D. Swyt, Summary Report of NIST/MSC Workshop on Traceability in Length, NISTIR 4757, Natl. Inst. Stand. Technol., Apr. 1998.

[28] M. Postek and D. Joy, Submicrometer microelectronics dimensional metrology: scanning electron microscopy, J. Res. Natl. Bur. Stand. (U.S.) 92, 187- 204 (1987).

[29] D. Stieren, The development of a national metrology infrastructure for the domestic gear industry, NISTIR 93-5215, Natl. Inst. Stand. Technol. (1993).

[30] D. Swyt, Challenges to NIST: the impact of tightening tolerances in the U.S. discrete-parts manufacturing industry, NISTIR 4757, Natl. Inst. Stand. Technol., Jan.1992.

[31] E. Teague, F. Scire, and T. Vorburger, Sinusoidal profile precision roughness specimens, Wear 83, 61-73 (1982).

[32] T. Vorburger, J. Song, C. Giauque, T. Renegar, E. Whitenton, and M. Croarkin, Stylus-laser surface calibration system, Prec. Eng. 19, 157-163 (1996). 
[33] R. Silver, J. Potzick, F. Scire, C. Evans, M. McGlauflin, E. Kornegay, and R. Larrabee, A method to characterize overlay tool misalignments and distortions, Proc. SPIE 143, 3050 (1997).

[34] D. Swyt, New concepts in precision dimensional measurement for modern manufacturing, in Control and Dynamic Systems, Vol. 45, C. T. Leondes, ed., Academic Press, New York (1992) pp. 111-163 (p.122).

[35] J. Fu, M. Croarkin, and T. Vorburger, The measurement and uncertainty of a calibration standard for the scanning electron microscope, J. Res. Natl. Inst. Stand. Technol. 99 (2), 191-199 (1994).

[36] J. Kramar, J. Jun, W. Penzes, E. Teague, J. Villarrubia, E. Amatucci, and D. Gilsinn, The molecular measuring machine, Proc. Intl Conf. Mechatronic Technology, (1998) p. 477.

[37] W. Estler, S. Phillips, B. Borchardt, T. Hopp, K. Eberhardt, M. McClain, Y. Shen, and X. Zhang, Practical aspects of touch trigger probe error compensation, Prec. Eng. 21, 1 (1997)

[38] J. Villarrubia, Morphological estimation of tip geometry for scanned probe microscopy, Surf. Sci. 321, 287 (1994).

[39] S. Phillips, B. Borchardt, D. Sawyer, and W. Estler, A constrained Monte Carlo simulation method for the calculation of CMM measurement uncertainty, Prec. Eng., in press (1999).

[40] S. Phillips and W. Estler, Calculation of measurement uncertainty using prior information, J. Res. Natl. Inst. Stand. Technol. 103 (6), 625-631 (1998).

[41] S. Phillips, K. Eberhardt, and W. Estler, Measurement uncertainty and uncorrected bias, Proc. NCSL, Charlotte NC (1999).

[42] R. Silver, T. Doiron, W. Penzes, S. Fox, and E. Kornegay, Two-dimensional calibration and measurement methodology, Proc. SPIE 3677, 37 (1999)

[43] J. Stoup and J. Doiron, A high-accuracy micrometer for diameter measurements of cylindrical standards, Proc. Meas. Sci. Conf., Anaheim CA (1994)

[44] J. Fu, J., V. Tsai, R. Koning, R. Dixson, and T. Vorburger, Algorithms for calculating single-atom step heights, Nanotechnology 10, 428 (1999).

[45] R. Silver, C. Jensen, V. Tsai, J. Fu, J., Villarrubia, and E. Teague, Developing a method to determine linewidth based on counting the atom spacings across a line, Proc. SPIE 3332, 441 (1998).

[46] Agility Forum, Next-Generation Manufacturing: A Framework for Action, Bethlehem, Pennsylvania (1997) p.11.

[47] D. Swyt, Challenges to NIST: The impact of tightening tolerances in the U.S. discrete-part manufacturing industry, NISTIR 4757, Natl. Inst. Stand. Technol., Jan. 1992.

[48] D. Swyt, Design, Tolerancing and assembly of micrometer-tolerance assemblies, NISTIR 5615, Natl. Inst. Stand. Technol., Mar.1995.

[49] Intel Microprocessor Hall of Fame, History of the microprocessor, http://www.intel.com/intel/museum/25anniv/hof/moore.htm (2000).

[50] NSIC, Head Metrology Requirements Roadmap, National Storage Industry Consortium, San Diego CA (1997) p. 2.

[51] SIA, The National Technology Roadmap For Semiconductors, Semiconductor Industry Association, third edition, San Jose CA (1997) p. 85.

[52] D. Swyt, Technical Directions of the Precision Engineering Division 1997-2001: Roadmaps for the Division's Research, Measurement Services, and Standards Committee Activities, NISTIR 6218, Natl. Inst. Stand. Technol., Jul. 1998.

[53] J. Stone, A. Stejskal, and L. Howard, Absolute interferometry with $670 \mathrm{~nm}$ external cavity diode laser, Appl. Opt. 38, 5981 (1999).
[54] International Organization for Standards, Standard reference temperature for industrial length measurements, ISO 1:1975, Geneva, Switzerland (1975).

[55] J. Song, F. Rudder, T. Vorburger, A. Hartman, B. Scace, and J. Smith, Microform calibrations in surface metrology, Int. J. Mech. Tools Manuf. 35 (2), 301-310 (1995).

[56] J. F. Song, S. Low, D. Pitchure, A. Germak, S. DeSogus, T. Polzin, H. Q. Yang, H. Ishida, and G. Barbato, Establishing a Worldwide Unified Rockwell Hardness Scale with Metrology Traceability, Metrologia 34, 4 (1997).

[57] T. Vorburger, J. Dagata, G. Wilkening, and K. Iizuka, Characterization of surface topography, in Methods of Surface Characterization, Vol. 5, Plenum Press, New York (1998).

[58] D. Nyyssonen and R. Larrabee, Sub-micrometer linewidth metrology in the optical microscope. J. Res. Natl. Bur. Stand. (U.S.) 92, 205-228 (1987).

[59] M. Postek and A. Vladar, Critical dimension metrology in the scanning electron microscope, Handbook of Silicon Semiconductor Metrology, Alain Diebold, ed., Marcel Dekker, New York (2000).

[60] J. Villarrubia, Tip characterization for dimensional nanometrology, Industrial SXM Techniques, H. Fuchs, R. Colton, and S. Hosaka, eds., Springer-Verlag (1999).

[61] R. Silver, C. Jensen, V. Tsai, J. Fu, J., Villarrubia, and E. Teague, Developing a method to determine linewidth based on counting the atom spacings across a line, Proc. SPIE 3332, 441 (1998).

[62] J. Fu, J., V. Tsai, R. Koning, R. Dixson, and T. Vorburger, Algorithms for calculating single-atom step heights, Nanotechnology 10, 428 (1999).

[63] T. LeBrun et al., The NIST atomic-scale displacement metrology project, NIST Competence Program, Natl. Inst. Stand. Technol. (1999).

[64] J. Goldberg, Space-time, in Encyclopedia of Physics, R. Lerner and G. Trigg, eds., VCH Publishers, New York (1991) p. 1158.

[65] The International Dictionary of Physics and Electronics, 2nd ed., D. Van Nostrand Company, Princeton, New Jersey (1961) p. 561.

[66] V. Braginsky, Y. Vorontsov, and K. Thorne, Quantum non-demolition measurements, Science 209, 547 (1980).

[67] E. Teague, Nanometrology, Proc. AIP Conf. Scanned Probe Microscopy, Santa Barbara CA (1991).

[68] F. Reif, Fundamentals of Statistical and Thermal Physics, McGraw Hill Book Company, New York (1965) p. 300.

[69] W. Lee, J. Shirley, J.Lowe, and R. Drullinger, The accuracy evaluation of NIST-7 (cesium beam primary frequency standard), IEEE Trans. Instru. Meas. 44, 120-123 (1995).

[70] S. Jefferts, D. Meekhof, J. Shirley, T. Parker, C. Nelson, F. Levi, G. Costanzo, A. De Marchi, R. Drullinger, L. Holberg, W. Lee, and F. Walls, Accuracy evaluation of NIST-F1, Metrologia, submitted (2000).

[71] D. Swyt, The uncertainty of dimensional measurements made at non-standard temperatures, J. Res. Natl. Inst. Stand. Technol. 99 (1), 31-44 (1994).

[72] W. Estler, High accuracy displacement interferometry in air, Appl. Opt. 24, 808 (1985).

[73] North American Metrology Cooperation, Traceability, NORAMET Document No. 7 (1997-04-23), Natl. Inst. Stand. Technol. (1997).

[74] International Organization for Standards, Geometrical Product Specifications (GPS): Master Plan, ISO/TR 14638:1995, Geneva, Switzerland (1995).

[75] D. Swyt, Metrological Issues in Precision-Tolerance Manufacturing: A Report of a NIST Industry-Needs Workshop, J. Res. Natl. Inst. Stand. Technol. 98, 245-252 (1993). 
[76] P. Bennich, Chains of Standards: A new concept in GPS standards, Mfg. Rev. 7, 29-35 (1994).

[77] D. Stieren, The NIST / DoE Oak Ridge Centers for Manufacturing Technology Collaboration in Dimensional Metrology, NISTIR 5482, Natl. Inst. Stand. Technol. (1994).

[78] D. Swyt, Strategic Program in the Shop Floor as NMI, NIST Manufacturing Engineering Laboratory, Internal Documents, Natl. Inst. Stand. Technol. (1999).

About the author: Dennis A. Swyt is a physicist and Chief of the Precision Engineering Division of the NIST Manufacturing Engineering laboratory, which is responsible for the realization and dissemination of the SI unit of length, including provision of NIST's dimensional measurement services. The National Institute of Standards and Technology is an agency of the Technology Administration, U.S. Department of Commerce. 